AROUEOLOGÍA Y SOCIEDAD

№ 26, 2013: 165-190

ISSN: 0254-8062

RECIBIDO: 21 / MAR. / 2013

ACEPTADO: 2 / MAY. / 2013

\title{
ESTUDIO DE HUACA DEL SOL DESDE LA TEORÍA GENERAL DE SISTEMAS DE NIKLAS LUHMANN
}

\author{
HENRY CHÁVARRI \\ Proyecto Aroueológico HuACA DEL SOl y de LA LUNA \\ henry_joel22@hotmail.com \\ MOISES TUFINIO \\ Proyecto ARQUEOLÓgico HuACA DEL SOL Y dE LA LUNA \\ motufinio@hotmail.com \\ PATRICIA GAMBOA \\ Proyecto Aroueológico HuACA DEL SOl y de LA LUNA \\ patricia.gamboag@hotmail.com
}

\section{RESUMEN}

Luego de varias investigaciones en Huaca del Sol (Uhle 1915; Hastings y Moseley 1975; Moseley 1975; Pozorski 1979; Gallardo y Narro 1992; Herrera y Ramírez 1992; Herrera y Chauchat 2003), el proyecto arqueológico Huacas de Moche inició un programa de investigaciones que comenzaron en el año 2011. De aquí, que en el presente artículo, se exponen los resultados obtenidos de las excavaciones en la sección 2 de Huaca del Sol desde el enfoque sistémico de Niklas Luhmann, que nos sirvió para conceptualizar y definir nuestro proceder frente a los temas particulares deslindados. Las conclusiones que ofrecemos muestran en primer lugar, un largo proceso autopoiético de construcción, donde se ha definido una secuencia constructiva de tres fases (última, penúltima y antepenúltima). De éstas, la penúltima está constituida por dos subfases, que estarían indicando una compleja funcionalidad del edificio, asociado al inicio a actividades doméstico-residencial y luego a actividades propias de un palacio; y en segundo lugar, se sugirió que el colapso Moche habría acontecido tras una crisis en el plano operativo donde salió a relucir problemas altamente abstractos y simbólicos de la comunicación.

Palabras Clave: Huaca del Sol, Teoría de Sistemas, diseño y secuencia arquitectónica, función, cronología, irritación.

\section{Abstract}

After several investigations in Huaca del Sol (Uhle 1915; Hastings and Moseley 1975, Moseley 1975; Pozorski 1979 Narro Gallardo and 1992, Herrera and Ramirez 1992; Herrera and Chauchat 2003), the archaeological project Huacas de Moche (Moche Temples) initiated a research program that began in 2011. In this article, we present the excavations results in section 2 of Huaca del Sol from the systemic approach by Niklas Luhmann, which helped us to conceptualize and define our procedure to the particular demarcated issues. The conclusions, we 
present, show in first place, a long building autopoietic process, which has defined a three-phase construction sequence (last, penultimate and antepenultimate. The penultimate phase consists of two sub phases, which would indicate a complex building functionality associated at the beginning to domestic-residential activities and then to palace activities; in second place, it was suggested that the Moche collapse would have occurred after a crisis at the operational level where abstract and symbolic communication problems appeared.

KEYwords: Huaca del Sol, The General systems Theory, design and architectural sequence, chronology, irritation.

\section{INTRODUCCIÓN}

El complejo arqueológico Huacas del Sol y de la Luna está ubicado en la margen izquierda del río Moche, en el valle bajo ${ }^{1}$. Domina un área de 60 ha, desde el pie de Cerro blanco y la rivera del río, destacando dos edificios monumentales hechos íntegramente de adobes paralelepípedos llamados Huaca de la Luna, situado al pie del cerro Blanco; y Huaca del Sol, apostado a medio kilómetro de ésta, y a cien metros del río moche, limitando por el norte con el cerro negro y por el sur con la campiña de Moche (Figs. 1 y 2).

Hoy en día, el contexto de la arqueología de investigación nos advierte de una carencia en la interpretación de los datos obtenidos de las excavaciones, puesto que se observa la tendencia de seguir con una arqueología empirista, que acentúa la experiencia y la percepción sensorial en la reflexión del pasado sin tener encuenta una articulación teórica. Este problema, a decir de Almudena (1992), parte de un deficiente sistema académico, dentro del cual no es prioridad el desarrollo de una actitud reflexiva y crítica del alumno acerca de nuestro pasado. Ante tal escenario, en el presente artículo proponemos recobrar la importancia de valerse de un marco teórico en arqueología, que de hecho autores como Trigger (1992) y Johnson (2000) ya lo habían destacado a inicios del siglo XXI. Así pues, para intentar responder a la problemática que encierra el sitio de Huaca del Sol, decidimos a favor del empleo de la Teoría General de sistemas de Niklas Luhmann², la misma que viene aplicándose en diferentes campos de las ciencias sociales, revelando una nueva forma de percibir las sociedades. Se trata, por tanto, de un esfuerzo teórico que muestra las nuevas tendencias ${ }^{3}$ de esta teoría, conocida también como tercer paradigma sistémico ${ }^{4}$, que nos servirá para conceptualizar y definir nuestro proceder frente a los temas particulares deslindados.

1 Geográficamente se ubica 7859'35» de longitud oeste y a 807’35» de latitud sur y a una altitud de $50 \mathrm{msnm}$ según la hoja $17 f$ - Salaverry del Instituto Geográfico Nacional (ONERN 1973). Políticamente se sitúa en la campiña de Moche, en el distrito de Moche, provincia de Trujillo, departamento de La Libertad.

2 Niklas Luhmann (1927-1998) es un sociólogo alemán considerado como el teórico de sistemas más destacado, que ha construido una de las obras más fecundas y singulares del siglo XX. El interés de Luhmann fue siempre entender las sociedades; por ello, parte de la teoría de sistemas para estructurar su propuesta analítica, ya que la consideró una teoría dinámica que podía explicar las diferencias de todo tipo en el interior de la sociedad y de los procesos sociales; no obstante, transforma radicalmente el uso que las ciencias sociales habían hecho de ella con anterioridad (López 2002).

3 Las nuevas tendencias de la propuesta Luhmaniana (1998:34) queda centrado en tres aspectos: interés por la autonomía y por una mayor sensibilidad ante el entorno; estabilidad dinámica y la auto-producción de todos aquellos elementos.

4 Ha habido históricamente tres paradigmas para describir a los sistemas: el 1er.paradigma partió de la tradición filosófica vétero europea, que consideró a los sistemas como conjuntos de partes correlacionadas (todo/parte); el 2do. paradigma surgió de la distinción sistema/entorno de Bertalanfly, en donde el sistema se define siempre respecto a un determinado entorno; y el 3er.paradigma pertenece a la sistemática de Luhmann (elemento/relación) que incorpora el concepto de autorreferencia, para indicar que el sistema contiene en sí mismo la diferencia con su entorno; estableciendo con ello importantes diferencias con respecto al paradigma anterior. 


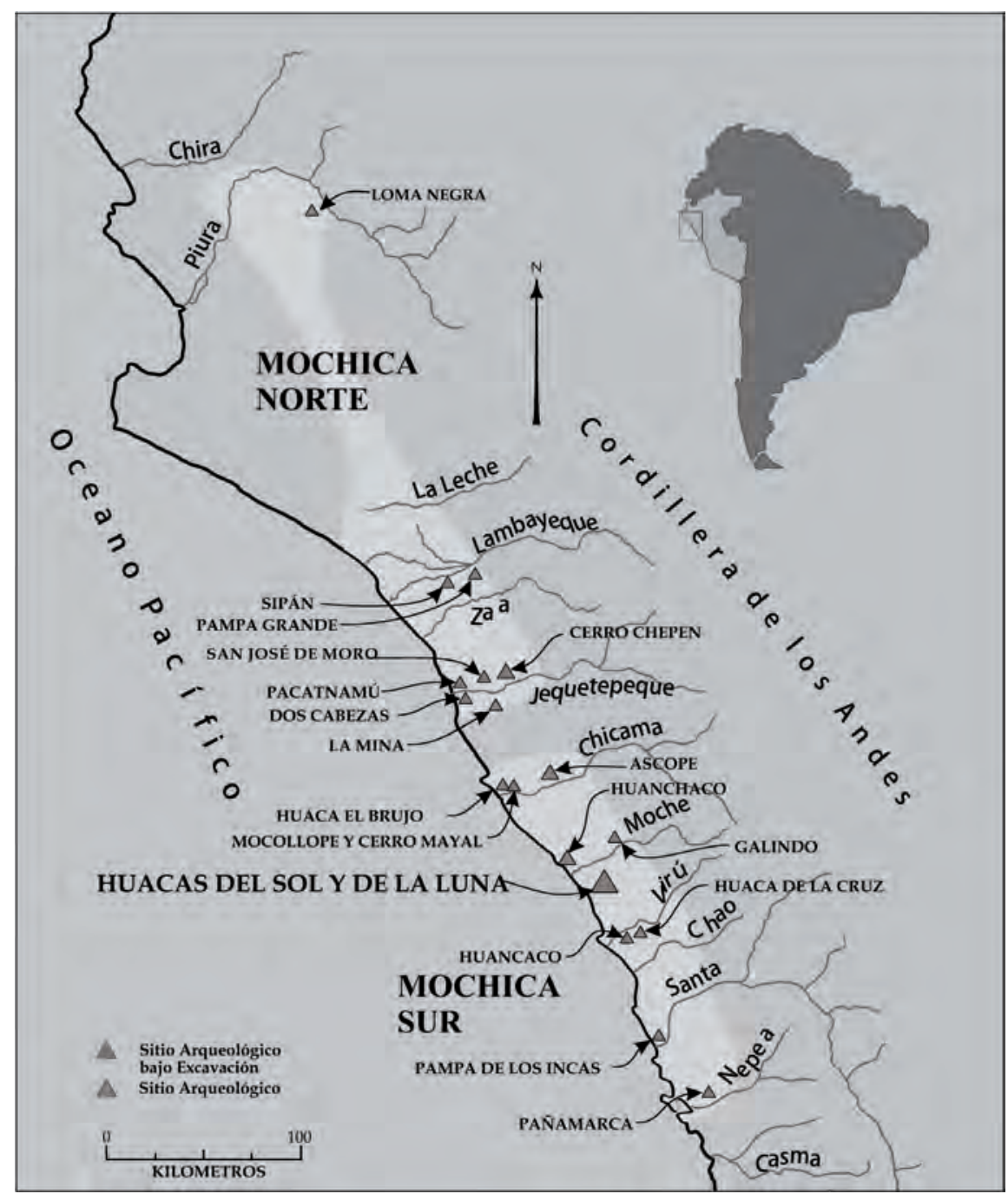

Figura 1. Ubicación del sitio arqueológico Huaca del Sol y de la Luna en la costa Norte del Perú.

Al respeto, el contenido de este escrito se organiza en base a los siguientes temas: Diseño y secuencia constructiva, cronología, funcionalidad e irritación del sistema teocrático Moche. No obstante, antes de su desarrollo, creemos necesario precisar en un breve preámbulo los aspectos más representativos de la «Teoría General de sistemas», así como definir nuestra metodología a seguir.

\section{Enfoque Sistémico de Niklas LuhManN: Definiendo SU PROpUesta}

Este tercer paradigma sistémico tiene un punto de partida esencial que estriba en el reconocimiento de la complejidad ${ }^{5}$ producto de la diferenciación de la sociedad; y en exigir que toda teoría deba ser un arma para reducirla (Campos et al 2010). Esta diferenciación consiste en establecer relaciones sistema/entor-

5 Entiende Luhmann por complejidad, a la sobreabundancia de relaciones, de posibilidades, de conexiones, de modo que ya no pueda ser posible plantear una correspondencia biunívoca y lineal de elemento con elemento (Campos et al 2010). 


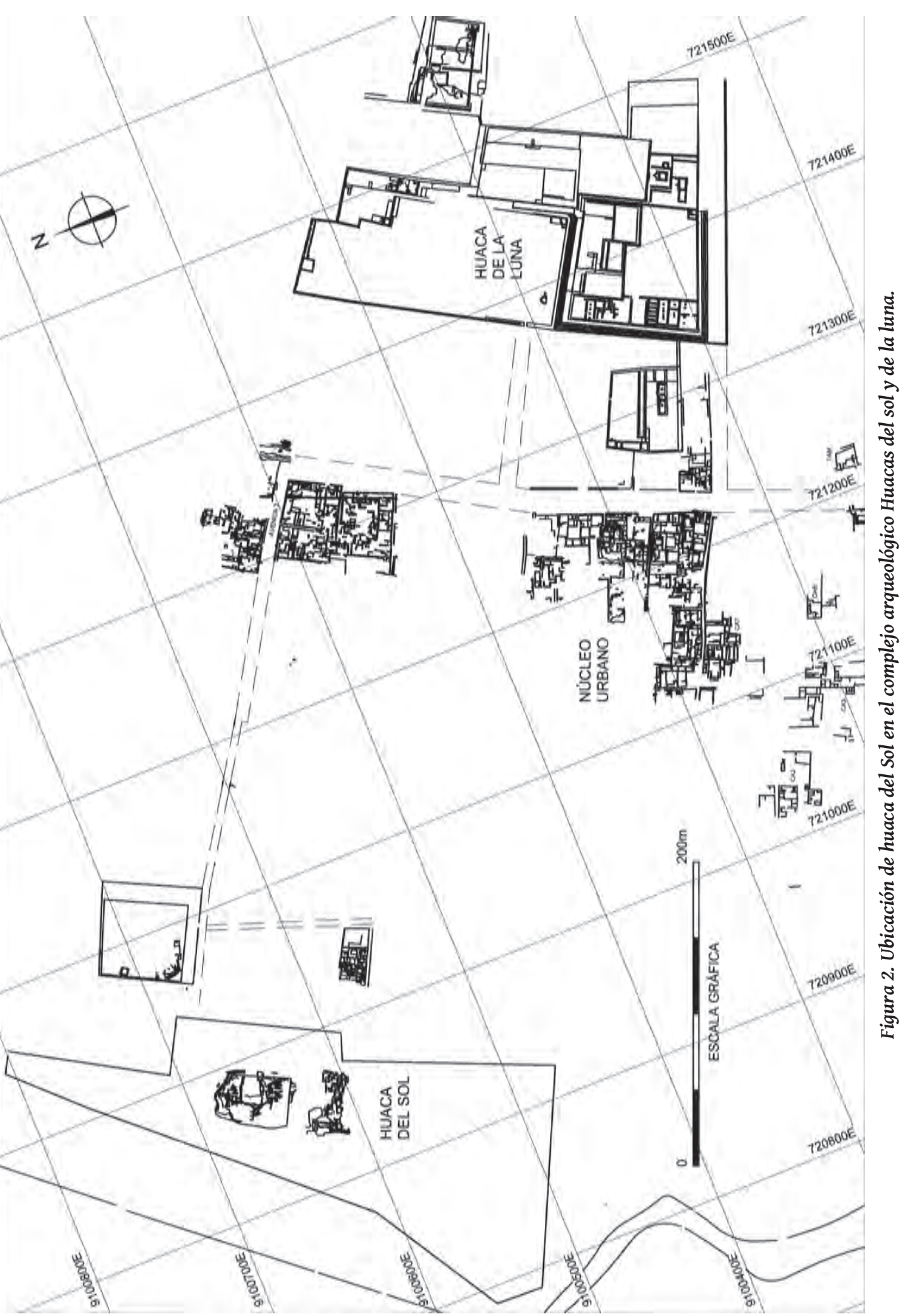


no y sistema/sistema; y admitir los conceptos de clausura operativa ${ }^{6}$, autorreferencia $a^{7}$ y autopoiesis ${ }^{8}$ en los sistemas. A partir de ello, Luhmann afirma que las sociedades son sistemas autorreferentes y autopoiéticos que cumplen las siguientes características: producen sus propios elementos básicos, sus propios límites y estructuras, es autorreferencial y es cerrado. Apunta a la comunicación como su unidad básica y ubica a los seres humanos como parte de su entorno y no componentes de la misma.

En suma, resulta de importancia que no sólo conozcamos el bagaje conceptual ${ }^{9}$, sino que además, seamos capaces de ponerlo en práctica; por tal motivo, veremos ahora la metodología a seguir en nuestra investigación:

\section{Metodología}

La propuesta analítica de Luhmann (2006), se organiza en base a esquemas de distinción orientados a hacer posible la observación de los sistemas sociales. Su aplicación en el sitio de Huaca del Sol responde a la necesidad de analizar la problemática propia de su secuencia constructiva, cronología, funcionalidad e irritación del sistema Moche; basándonos, para ello, en los conceptos de diferenciación, autopoiesis y clausura operativa.

La diferenciación, es el concepto decisivo para entender la formación histórica de las sociedades (Varela 1992); la cual expone dos diferencias básicas: la primera, la diferencia sistema/entorno y luego una segunda diferencia constitutiva: la existente entre elemento y relación. En los dos casos la diferencia es una unidad, pero sólo produce efectos como diferencia.

La diferencia sistema/entorno ${ }^{10}$ se constituye cuando el sistema traza sus límites mediante una marcación simbólica con respecto a su entorno (Luhmann 2006). Aquí se expresa el hecho de que todo sistema, reduciendo y organizando complejidad, genera ámbitos específicos de autonomía que pueden terminar por fragmentar el sistema y alumbrar en su seno subsistemas funcionalmente diferenciados (García 1999). Así, se podrá segmentar un fenómeno social en partes y en diferentes niveles de profundidad, estudiándolos como sistemas unitarios dotados de identidad.

La diferencia elemento ${ }^{11} /$ relación desemboca en la teoría de la complejidad de los sistemas; que sólo mediante esta distinción adquiere sentido [...] el que la complejidad del sistema aumente al cre-

6 Clausura operativa indica como el sistema impone una necesaria clausura de sus operaciones para llevar a cabo su autorreferencia y con ello la diferencia del sistema con su entorno (Amozurrutia 2007). En este sentido, la comprensión de toda cultura, sólo es posible develando su lógica interna; contraponiéndose así al enfoque sistémico-adaptativo de Binford.

7 La autorreferencia indica el hecho de que existen sistemas que se refieren a sí mismos mediante cada una de sus operaciones. Menciona cuatro tipos básicos: las máquinas, los organismos, los sistemas síquicos (entiéndase: al hombre) y los sociales. Todos y cada uno de ellos son sistemas pero también tienen su propia naturaleza (Mélich 1996: 17-18).

8 El concepto de autopoiesis o autoproducción fue formulado por el biólogo chileno Humberto Maturana, al intentar dar una definición a la organización de los organismos vivos, los mismos que se caracterizan por la capacidad de producir yreproducir sus elementos que definen su propia unidad. De aquí que Luhmann adopta este concepto para lo social y amplía su importancia (Corsi et al 1996: 31-32).

9 Véase el glosario sobre la teoría social de Niklas Luhmann (Corsi et al 1996).

10 Opera como una suerte de lente bifocal en que un foco se ocupa del sistema y el otro del entorno. Como en los gráficos de figura y fondo, no se puede ver uno sin el otro (Mansilla y Nafarrate 2008). Así de entrada, la delimitación sistema/entorno permite hacer cortes en los objetos que no eran posibles con otras disposiciones teóricas (Luhmann 2006: 8).

11 El concepto elemento indica lo que para el sistema es una unidad y que existen sólo en relación con otros elementos (Corsi et. al 1996). 
cer la diferenciación (Luhmann 1998). A su vez, estos elementos al ser colocados en un cierto orden, le permiten al sistema la formación de estructuras ${ }^{12}$ que les proporciona sostén y estabilidad (López 2002). De ahí, que su manejo nos servirá para definir en el monumento sus estructuras arquitectónicas ${ }^{13}$ (elemento arquitectónico/relación) y aproximarnos a la funcionalidad de las mismas (asociación entre elemento cultural mueble/relación y estructura arquitectónica; así como elemento iconográfico/relación).

Así también, la diferenciación a lo largo de su evolución temporal, muestra a los sistemas en constante movimiento, expansión y/o contracción (Luhmann 1991); esto debido a que sus estructuras ${ }^{14}$ son abiertas al cambio y capaces de aprender (Corsi et al. 1996). Este proceso de carácter autorreferencial nos llevará a comprender en lo social, los cambios organizacionales que se manifiestan en la cultura material.

La autopoiesis, por su parte, entendida como «la operación de autorreproducción de un sistema, mediante la que el sistema crea su propia estructura y los elementos que la componen» (Izuzquiza 1990: 111); nos ayudará a definir los cambios acontecidos en la sociedad Moche a nivel social, económico, iconográfico, ideológico y arquitectónico. Todo ello, responde a un patrón o esquema reticular; sin embargo, hemos considerado diagramar sólo las relaciones estratigráficas haciendo uso de un tipo de esquema en red con el que estamos bastante familiarizados, el de la matriz de Harris, un tipo de diagrama que ancla perfectamente en los presupuestos sistémicos, en tanto que se trata de una representación abstracta.

Finalmente, a través del estudio de las operaciones internas de su sistema (clausura operativa), podremos definir los procesos que llevaron a irritar o perturbar la sociedad Moche. Para tal fin, utilizaremos el concepto de form $a^{15}$ en el sentido técnico de la teoría de sistemas autorreferenciales, esto es, como un espacio dividido en dos por una distinción; lo cual nos permitirá ubicarnos en la política ejercida al final de los Moche.

En síntesis, vemos que el interés de la presente teoría no es abstracto, sino aplicado a dar cuenta de los fenómenos sociales (Varela 1992). Por ello, tenemos que a continuación se dispondrá de esta metodología descriptiva, explicativa y de síntesis para dar cuenta de los siguientes ítems:

\section{ARQUITECTURA}

Se abordará cuatro temas de interés: diseño y secuencia constructiva, cronología y funcionalidad del edificio.

\section{Diseño y secuencia constructiva}

La complejidad que muestra la arquitectura de la sección 2 de Huaca del Sol como diferencia topográfica ${ }^{16}$ (Figs. 3, 4 y 5), obedece a las mismas necesidades de poder y control al instituirse un estado secular; es

12 Las estructuras son condiciones que delimitan el ámbito de relación de las operaciones de un sistema, sin necesidad de un aparato formal o material (Corsi et al. 1996).

13 Las estructuras arquitectónicas responden específicamente a la corporeización física del sistema. En la sección 2 de Huaca del Sol, hemos considerado el concepto de unidad estructural arquitectónica (UEA) como unidad espacial, término neutro que no conlleva una asignación funcional del espacio ni interpretativa alguna.

14 Desde una vista temporal, las estructuras responden a un axioma de la gestión organizacional que dice: «la estructura sigue a la estrategia» (Chandler 1962), con lo cual se remarca que las estructuras de una organización deben ser cambiables, en la medida que se respete el espacio y los propios intereses de las personas (Rodriguez 2001).

15 La idea de forma está en el centro de la epistemología sistémica y de su derivado necesario, la teoría de la observación. Una forma debe entenderse «como límite, como la marca de una diferencia que obliga a dejar en claro cuál es el lado que se indica, esto es, en qué lado de la forma uno se encuentra».

16 La diferencia topográfica consiste en delimitar un ámbito propio frente a su entorno. 


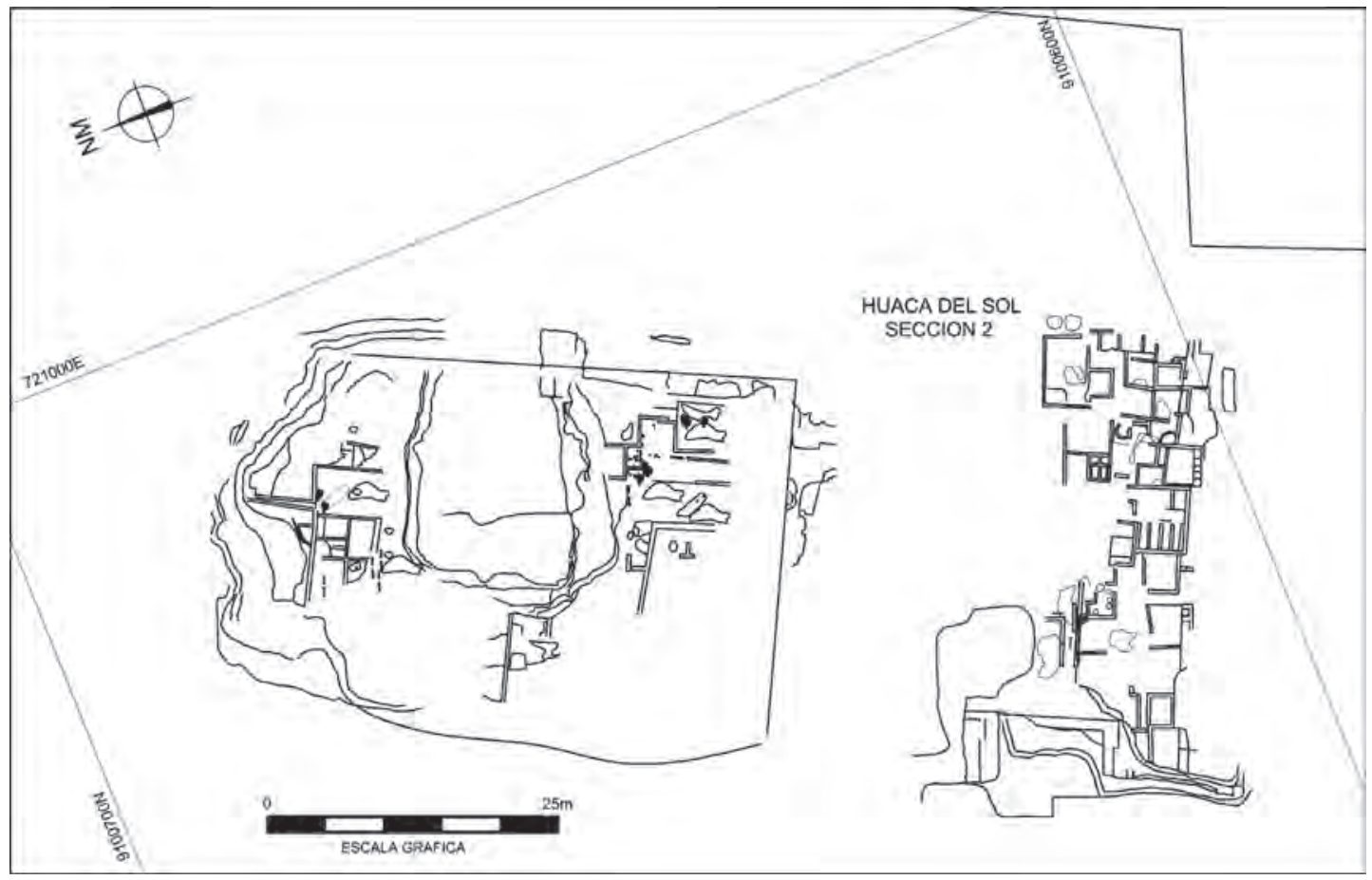

Figura 3. Arquitectura definida en la sección 2 de Huaca del Sol.

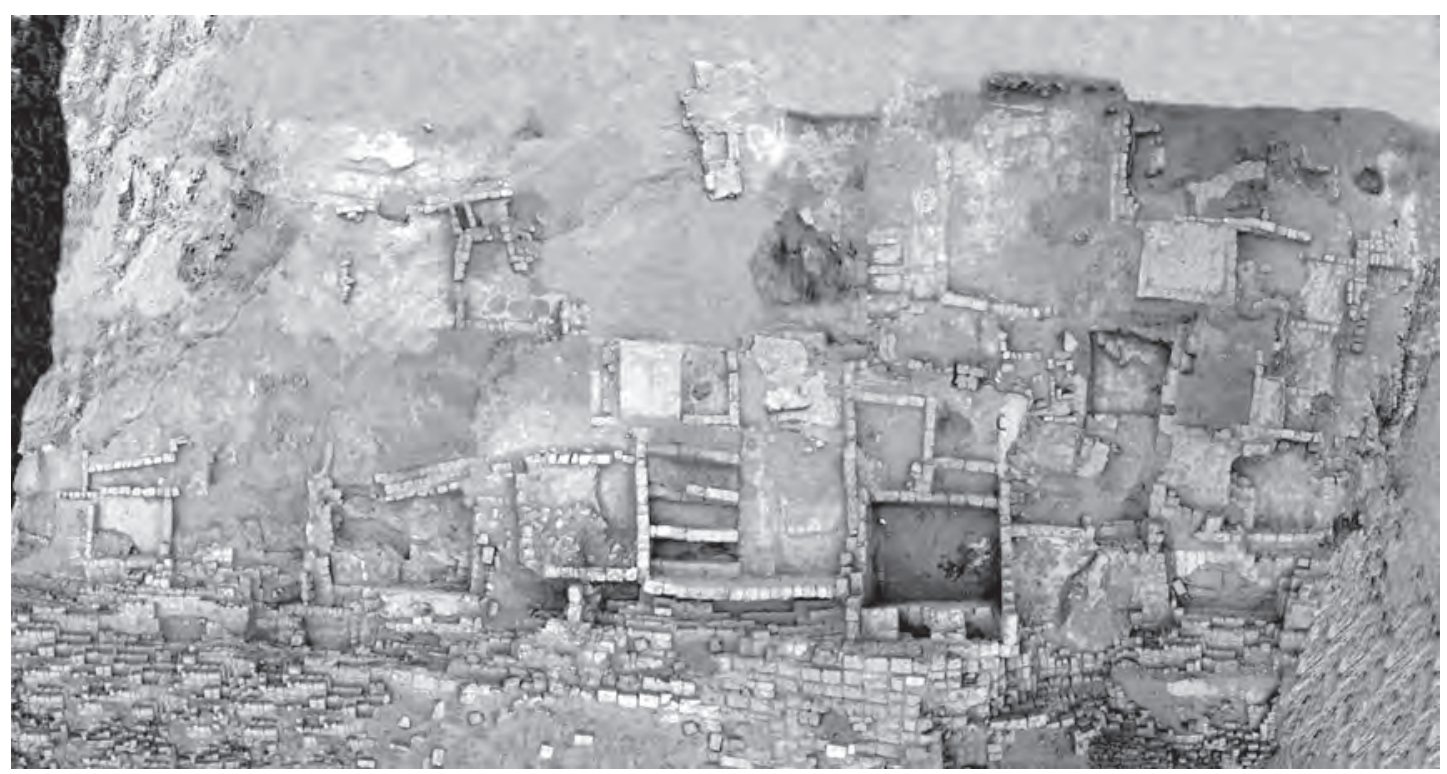

Figura 4. Vista de planta de UEA ubicados en el lado sur de la sección 2. 


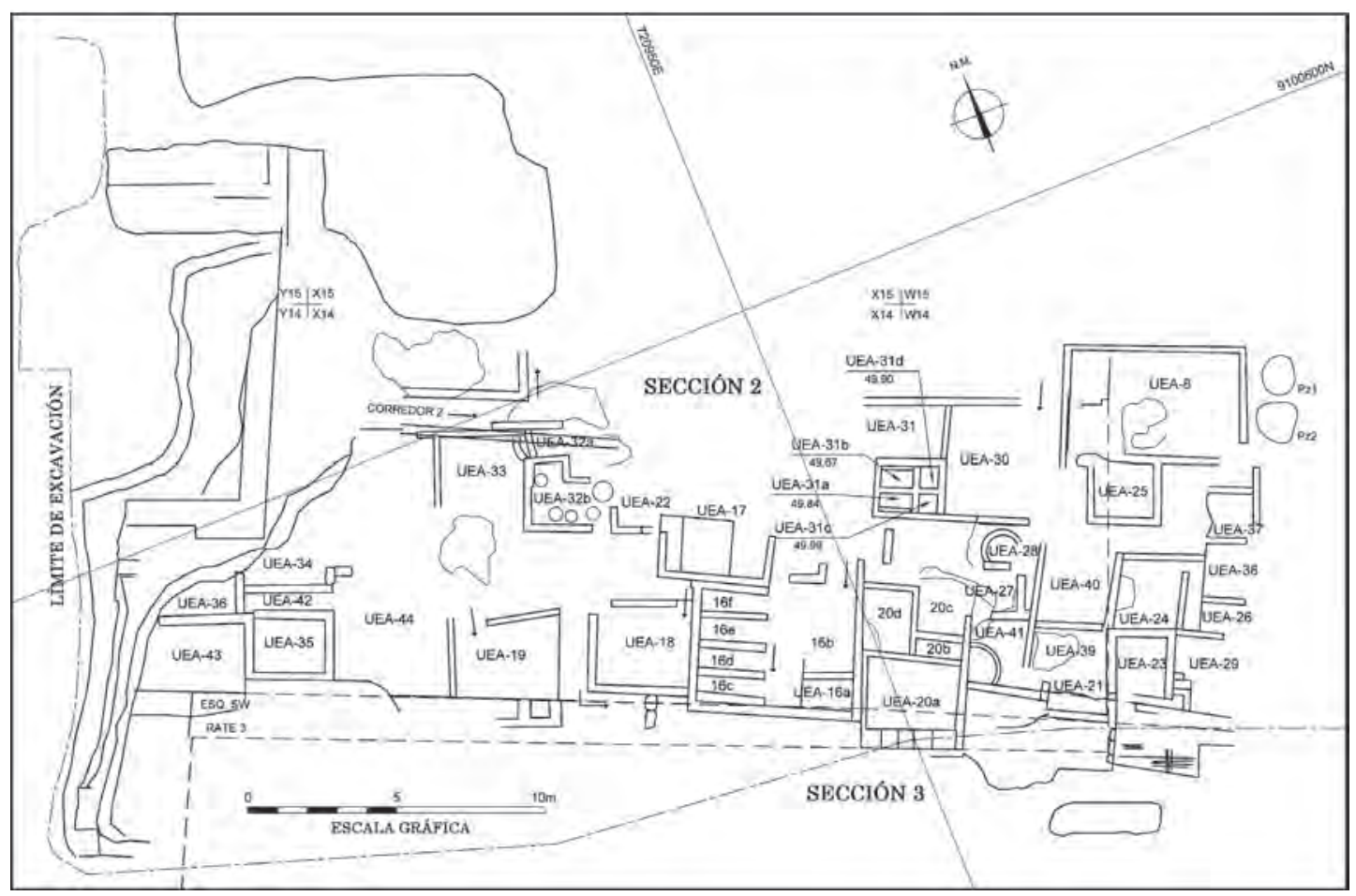

Figura 5. Plano general de UEA ubicados en el lado sur de la sección 2.

decir fueron el reflejo de los cambios sociales y políticos operados en esta sociedad para los tiempos finales de los Moche.

Partiendo de esta premisa, nuestras investigaciones en la sección 2 de Huaca del Sol nos han permitido definir un proceso autopoiético de edificación, dado que se construirían los edificios cada cambio de nuevo señor, o cuando alguno de estos señores que gobernaron tuvieron el poder suficiente para hacerse obras de gran envergadura. Así, se desmontaba parcialmente la vieja arquitectura para construir una nueva; que no necesariamente estaría asociado a un nuevo proyecto de ampliación de la plataforma donde estaba construido el edificio. De aquí, la diferencia con el edificio de Huaca de la Luna, donde su renovación implicaba enterrar el viejo templo conservándolo íntegramente y construyendo uno nuevo. Todo ello realizadodentro de calendarios religiosos con fechas fijas.

Una primera observación de la complejidad interna del edificio nos muestra una autopoiesis constructiva definida en una secuencia de tres fases (antepenúltima, penúltima y última (Fig. 6). Ubicar cronológicamente estas fases es un tema complejo, del cual hasta el momento no poseemos ningún fechado absoluto que permita abordar su estudio con una mayor consistencia; sin embargo, hemos esbozado de manera preliminar una correlación entre las tres fases definidas y la secuencia elaborada por Larco (1948) para la cerámica mochica.

A continuación, se sustenta lo dicho líneas arriba, con la descripción de su autopoiesis arquitectónica (desde la fase más temprana a la más tardía) acompañada de su correlación cronológica (Fig. 7).

\section{Antepenúltima fase}

Esta fase ha sido registrada en el perfil oeste de la sección 2 (Fig. 8). Se observa un piso (P12) asociado a una terraza enlucida sin color, con un vano de acceso de umbral alto que generó una 


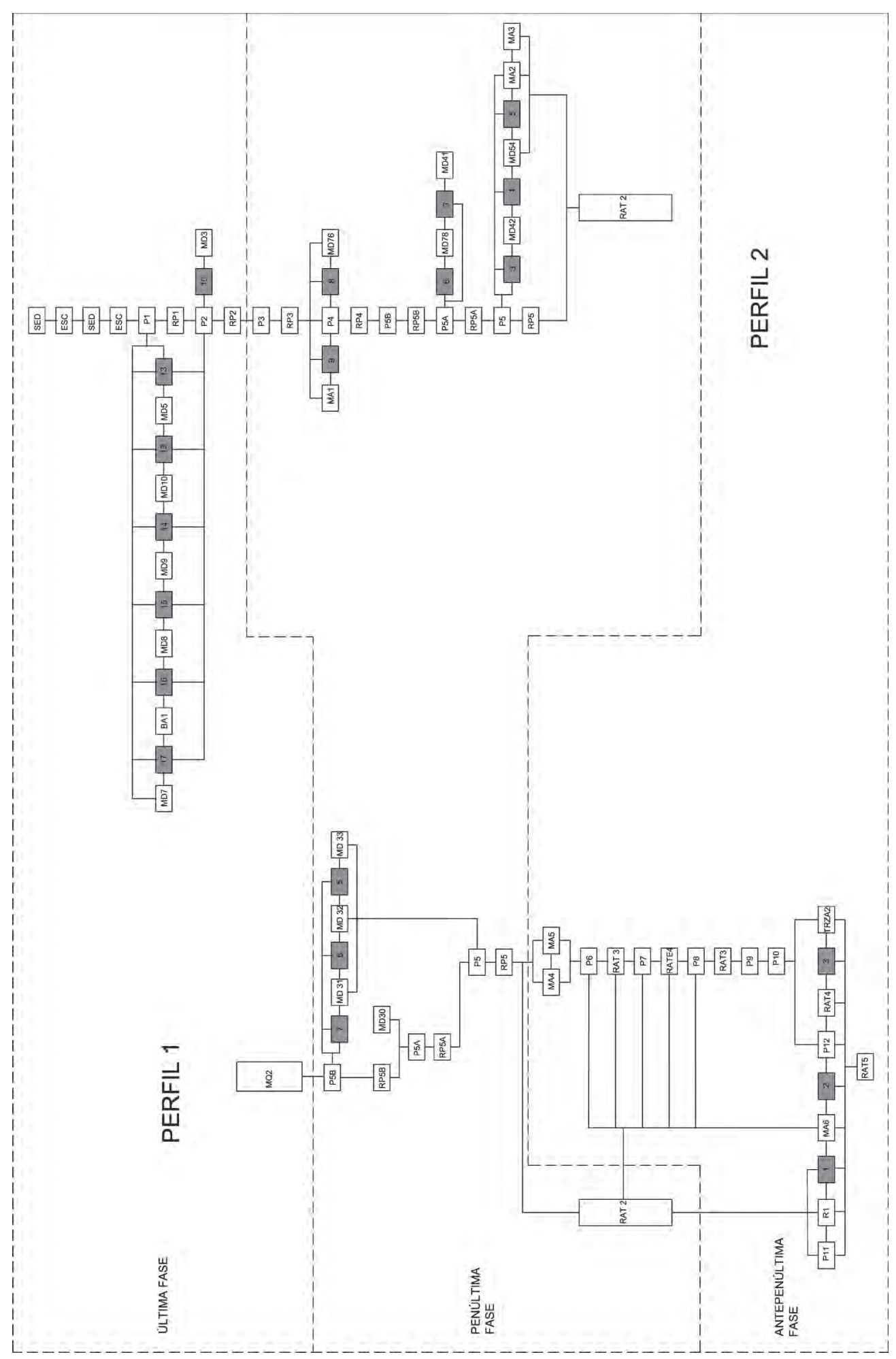

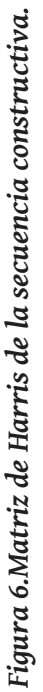




\begin{tabular}{|c|c|c|c|c|c|}
\hline \multicolumn{6}{|c|}{ ARQUITECTURA DE LA SECCIÓN 2 DE HUACA DEL SOL } \\
\hline Cronologia & $\begin{array}{c}\text { Fases } \\
\text { Constructivas }\end{array}$ & $\begin{array}{c}\text { Subfases } \\
\text { Constructivas }\end{array}$ & Descripción & Remodelaciones & Descripción \\
\hline Post Moche & Última & & $\begin{array}{l}\text { Construcción de muros de quincha intrusivos, } v \\
\text { las UEA } 16,18,19 \text { y } 20 \text { a nivel del piso } 2 \text {. }\end{array}$ & $1 *$ & $\begin{array}{l}\text { Construcción de muros de adobes } \\
\text { 5obre los muros de quincha } \\
\text { (UEA 43). Se remodelan los } \\
\text { UEA } 16,18,20 \text { y } 21 \text { con el piso } \\
\text { 1; y se intruyen fogones en la } \\
\text { arguitectura precedente. }\end{array}$ \\
\hline \multirow{4}{*}{ Moche IV } & \multirow{4}{*}{ Penúltima } & \multirow{3}{*}{ Subfase 2} & \multirow{3}{*}{$\begin{array}{c}\text { Se sella la fachada escalonada este y se construye } \\
\text { el piso } 5 \text { A asociado a la terraza } 1 \text { y a las } \\
\text { UEA : } 8,37,38,39,40,41,42 \text { y corredor } 2 \text {. }\end{array}$} & -3 & Piso $3:$ UEA 17 \\
\hline & & & & $2^{*}$ & $\begin{array}{c}\text { Piso } 45 \text { UEA } 17,22,23,24,25 \\
26,27,28 .\end{array}$ \\
\hline & & & & $1^{*}$ & $\begin{array}{c}\text { Piso 5B: UEA 29, 30, 31, 32, } \\
33,34,35,44 .\end{array}$ \\
\hline & & Subfase 1 & $\begin{array}{l}\text { La antepenútima fase es seilada por el RAT2 y el } \\
\text { piso } 5 \text {. La fachada este de la sección } 2 \text { es } \\
\text { escalonada y se construyen las UTEA } \\
12,13,14 \text { y } 15 \text { sobre las plataformas. }\end{array}$ & & \\
\hline \multirow{4}{*}{ Moche III } & \multirow{4}{*}{ Antepenúlitima } & & \multirow{4}{*}{$\begin{array}{l}\text { Funcionamiento del MA6 con una rampa en el } \\
\text { lado este y en el lado oeste, una terraza con vano } \\
\text { de umbrai alto, sobre el piso } 12 \text { y terminada en el } \\
\text { piso } 9 \text { sobre la terraza. }\end{array}$} & $4^{*}$ & $\begin{array}{c}\text { El piso } 7 \text { es sellado por el RATE3. Se } \\
\text { construye el piso } 6 \text { asociado al MA4 } \\
\text { yel MAS. }\end{array}$ \\
\hline & & & & $3^{*}$ & $\begin{array}{l}\text { El piso } 8 \text { es sellado por el RATE } 4 \text { y se } \\
\text { construye el piso } 7 \text {. }\end{array}$ \\
\hline & & & & $2^{*}$ & $\begin{array}{l}\text { Desmontan parcialmente el MA6 y la } \\
\text { arquitectura del lado oeste de la } \\
\text { subfase } 1 \text { es sellada con la } \\
\text { construcción del RAT3 y el piso } 8 \text {. }\end{array}$ \\
\hline & & & & $I^{*}$ & $\begin{array}{l}\text { Se sella el vano y se construye el } \\
\text { piso } 9 \text { sobre la terraza } 2 \text {. }\end{array}$ \\
\hline
\end{tabular}

Figura 7. Cuadro de la secuencia constructiva y su correlación cronológica de la arquitectura.

dificultad y sobretodo cierta restricción a una posible UEA ${ }^{17}$. Se le asocia a su lado oeste un muro ancho (MA6) y una rampa (R1) orientada de sur a norte, del cual se desconoce su comunicación hacia el otro nivel más alto y de mayor importancia. Toda esta arquitectura se encontró sellada por cuatro remodelaciones que pasamos a describir:

Primera remodelación. El vano de acceso fue clausurado por un relleno de adobes tramados (RAT4) que posteriormente fue enlucido siguiendo la estética de la fachada norte de esta terraza. Con este sello, se observa una reutilización de la terraza mediante la construcción de otro piso (P9).

Segunda remodelación. Se inicia con la destrucción parcial de un muro ancho (MA6), pues desmontan adobes de la parte norte, para luego sellar la arquitectura del lado oeste (P12, Terraza 2, P9 y el MA6) con el RAT3, que es rematado por un piso (P8) desde el paramento este del MA6 (lo que quedó en el lado sur) hacia el oeste, a una altura absoluta de 43,82 msnm. Paralelamente a esta construcción se observa que en el lado este continúa funcionando R1.

Tercera remodelación. El P8 es sellado por un relleno de adobes tramados (RATE4), donde se asienta un piso (P7) a 45,47 msnm. El enlucido de este RATE4 estaría funcionando como una fachada este, pues en esta sub fase continúa funcionando R1 en el lado este.

Cuarta remodelación. Corresponde a las últimas construcciones de la antepenúltima fase. Se sella el P7 con la construcción de otro relleno de adobes tramados (RATE3) cuyo enlucido incrementa la altura de la fachada este; en la parte superior remata con la construcción de un piso (P6) sobre el cual se construye un muro ancho (MA4) orientado de sur a norte, en cuyo paramento oeste se

17 Para el caso de Huaca de la Luna, se denominan recintos o ambientes a los espacios cerrados, techados y con divisiones internas que pueden tener vanos de acceso con umbral alto o no; el soporte de los techos pudo haberse hecho mediante pilares o columnas de madera (Uceda 2000). 


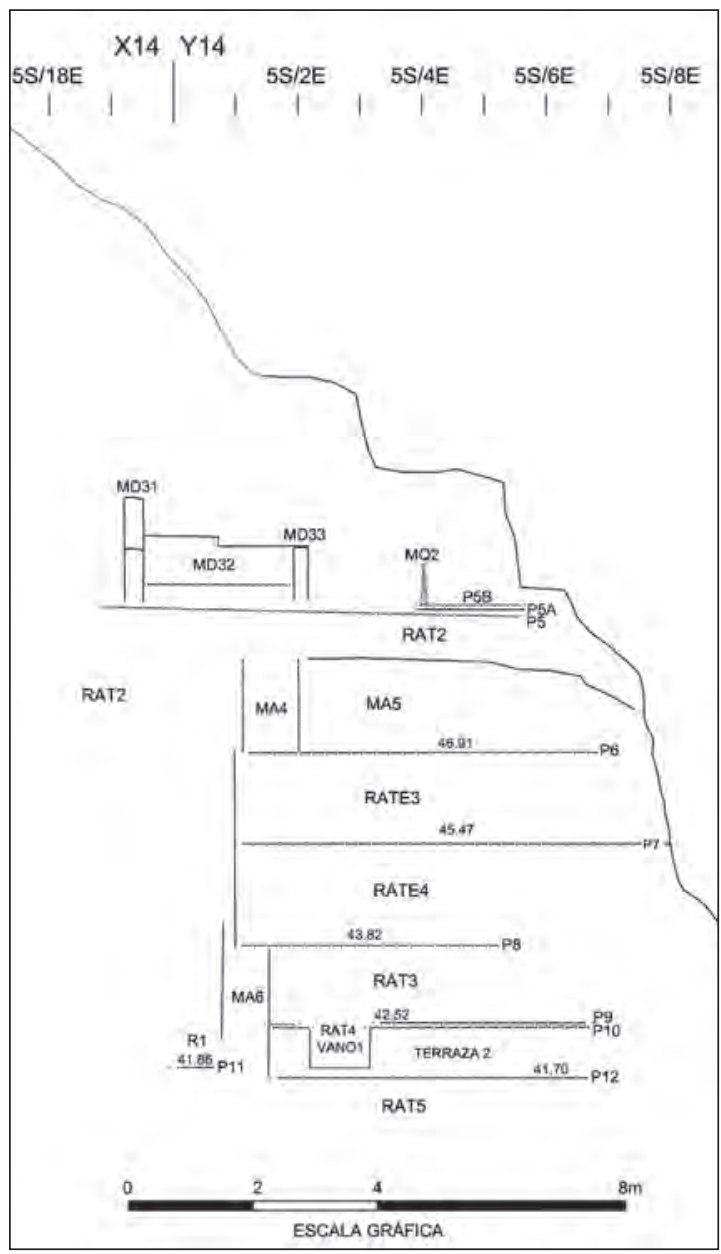

Figura 8. Perfil 1 ubicado en el lado oeste de la sección 2.

adosa otro muro ancho (MA5) orientado de este a oeste. Paralelamente a estas edificaciones se continúa utilizando R1 en el lado este.

Correlación altimétrica: Si correlacionamos altimétricamente el P12 con los últimos pisos registrados por Herrera y Chauchat (2003); y los pisos registrados por Gallardo y Narro (1992), tendríamos que nuestra antepenúltima fase correspondería a Moche III siguiendo la clasificación de Larco (1948).

\section{Penúltima fase}

Es la mayor documentada de la sección 2, tanto en su arquitectura como en los contextos asociados. Presenta una diferenciación espacial, con una planificación en la disposición de unidades estructurales arquitectónicas (UEA) que no había sido registrada anteriormente (suman un total de 44 UEA); alcanzando con las construcciones y remodelaciones de sus estructuras un nivel superior y un mayor volumen del edificio. Se diferencia en su autopoiesis por estar constituida por dos subfases (Figs. 7 y 9 ).

Subfase 1. Se inicia tras el selló de la fase anterior por un relleno de adobes tramados (RAT2) que generó una fachada escalonada en el lado este de la sección 2. En la parte superior de este RAT2, se definió una plataforma (piso 5) a una altura absoluta de 49,90 msnm asociado a las UEA 12, 13, 14 y 15 (Fig. 10a).

Sub fase 2. Se caracterizó por la reedificación parcial, remodelación y reutilización de la arquitectura anterior. Se amplió el lado este de la sección 2, cubriendo la fachada escalonada con un relleno de adobes tramados, al igual que fue sellado la plataforma en la parte superior; y se construyó una terrazade $45 \mathrm{~m}$ de largo por $37 \mathrm{~m}$ de ancho por 1,30 $\mathrm{m}$ de alto que define el piso de ocupación 5A. Ésta terraza fue el eje ordenador de esta sección, con dos rampas que conducen a un ambiente principal o sala capitular, definido por la presencia de un trono, dos banquetas paralelas y las UEA 9-11.Se le asocia al sur un área administrativa definida por las UEA 8,37-43 y el corredor 2, cuyos cambios formales en los depósitos estuvieron en relación directa con la dinámica de crecimiento de la terraza. Sobre sus accesos, vemos que se orientan en dirección al patio delantero, por lo que quedó claro un funcionamiento independiente. La definición del acceso 1 que funcionó durante los pisos más tardíos, demostró que las secciones 2 y 3 fueron erigidas en un mismo proyecto constructivo. No obstante, por razones que aún ignoramos, este acceso fue sellado con un relleno de material suelto. Esta Subfase 2 presentó tres remodelaciones que pasamos a detallar (fig.10b):

Primera remodelación: Los cambios más significativos ocurren en la terraza y en el área administrativa, donde el piso de ocupación anterior fue renovado por otro piso (P5B) creciendo entre $20-40 \mathrm{~cm}$ de alto. En la terraza, se cubren las dos rampas de acceso al ambiente con banquetas y 


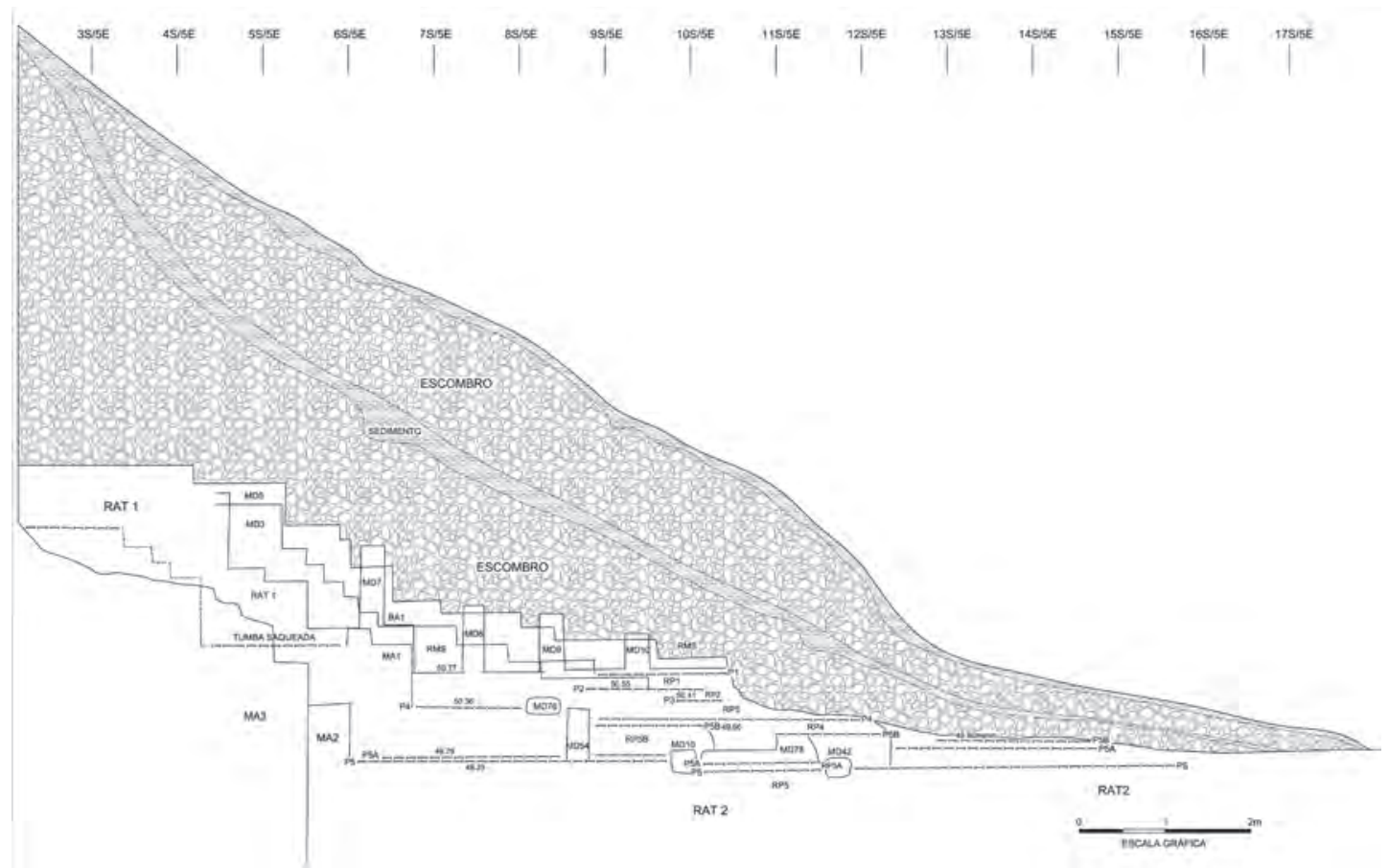

Figura 9. Perfil 2 ubicado en el lado sureste de la sección 2.

se construye una nueva rampa de acceso más al noroeste. No obstante, este ambiente también fue remodelado con nuevos muros al norte, este y oeste, manteniendo la apertura al sur. Al área administrativa, ubicada en el extremo sur de la sección 2, se le atribuye la construcción de nuevas UEA (29-36,44) (fig.10c).

Segunda remodelación: Se inicia con el sello del P5B por el nuevo piso (P4), creciendo $30 \mathrm{~cm}$ de alto. En la terraza, se siguió remodelando los muros de sus ambientes y sistemas de acceso, pero conservando su restricción. En el ambiente con banquetas su remodelación se centró en sus muros perimétricos y en las banquetas, conservando el uso de enlucido sin pintura. En el área administrativa, se siguió construyendo nuevas UEA (22-28) (Fig.10d).

Tercera remodelación: Se iniciacon el sello del P4 por el nuevo piso (P3)que debió ser uno de los más destruidos debido a su poca evidencia. En la terraza, solo tenemos registros para la UEA 9; en tanto, para el área administrativa, se observa en la UEA 17 (Fig. 10e).

Correlación altimétrica: Si hacemos la correlación altimétrica entre los pisos definidos durante nuestras investigaciones con la cerámica Moche IV ubicada por Moseley (1975) cerca de la cima de la sección 2; y la botella asa estribo registrada debajo del P5, entonces tendríamos que la penúltima fase correspondería a Moche IV (Fig. 7). Si nuestra lectura es correcta, en esta fase se puede observar una ocupación extensa iniciándose hacia el 400dC hasta el 850dC. De ello, tendríamos que la subfase 1 iría hasta los 750 d.c, donde el edifico fue más bajo y corto con escalones rojos y blanco en su flanco este; y que luego creció con la ampliación del lado este de la sección 2, construcción de la terraza y los depósitos asociados en la subfase 2 hasta el 850 dC. Con ello, desde una mayor perspectiva, tendríamos que tanto el último relleno constructivo de la sección 2 y 3, como la sección 1 y 4 son contemporáneas. A su vez, el dato arqueológico nos indica que a pesar de haber entrado en un proceso de cambio político, configurando un nuevo escenario y sobre todo por la acumulación de una serie de nuevos elementos provenientes de otros lugares y utilizados por la 
C

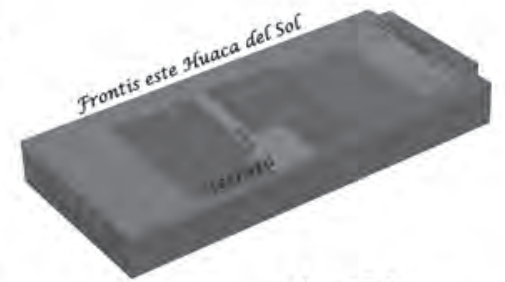

b
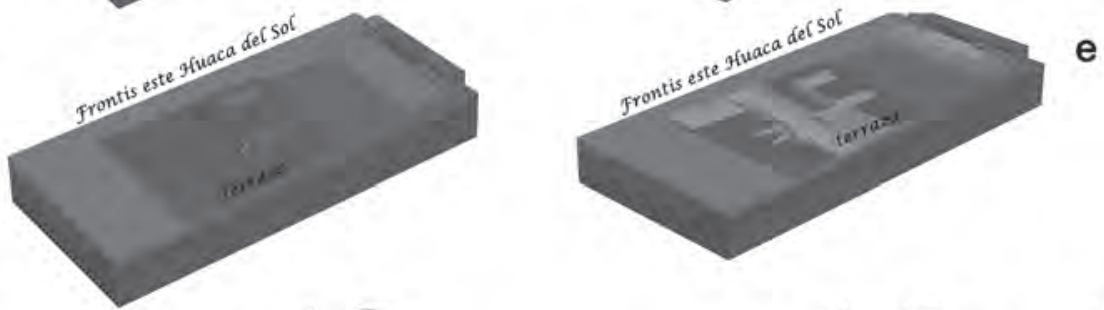

a

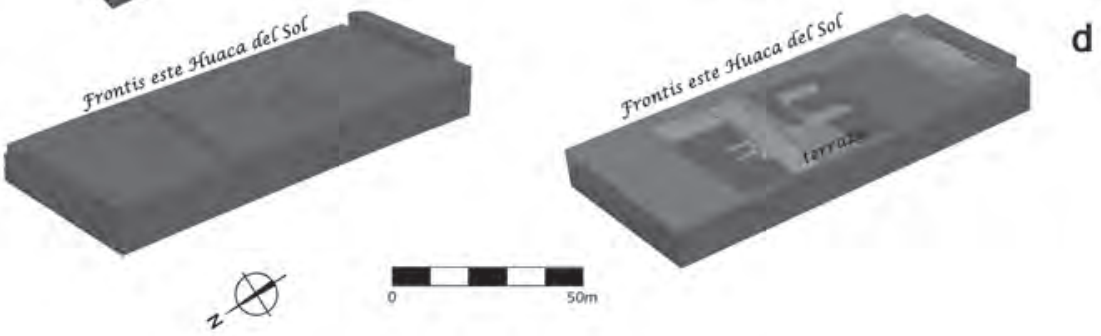

Figura 10. Reconstrucción isométrica de la secuencia constructiva.

clase dominante, la construcción de edificios públicos que hasta entonces se vino haciendo se detuvo y solo se hacían construcciones pequeñas, asociadas a remodelaciones (Fig. 11).

\section{Última fase}

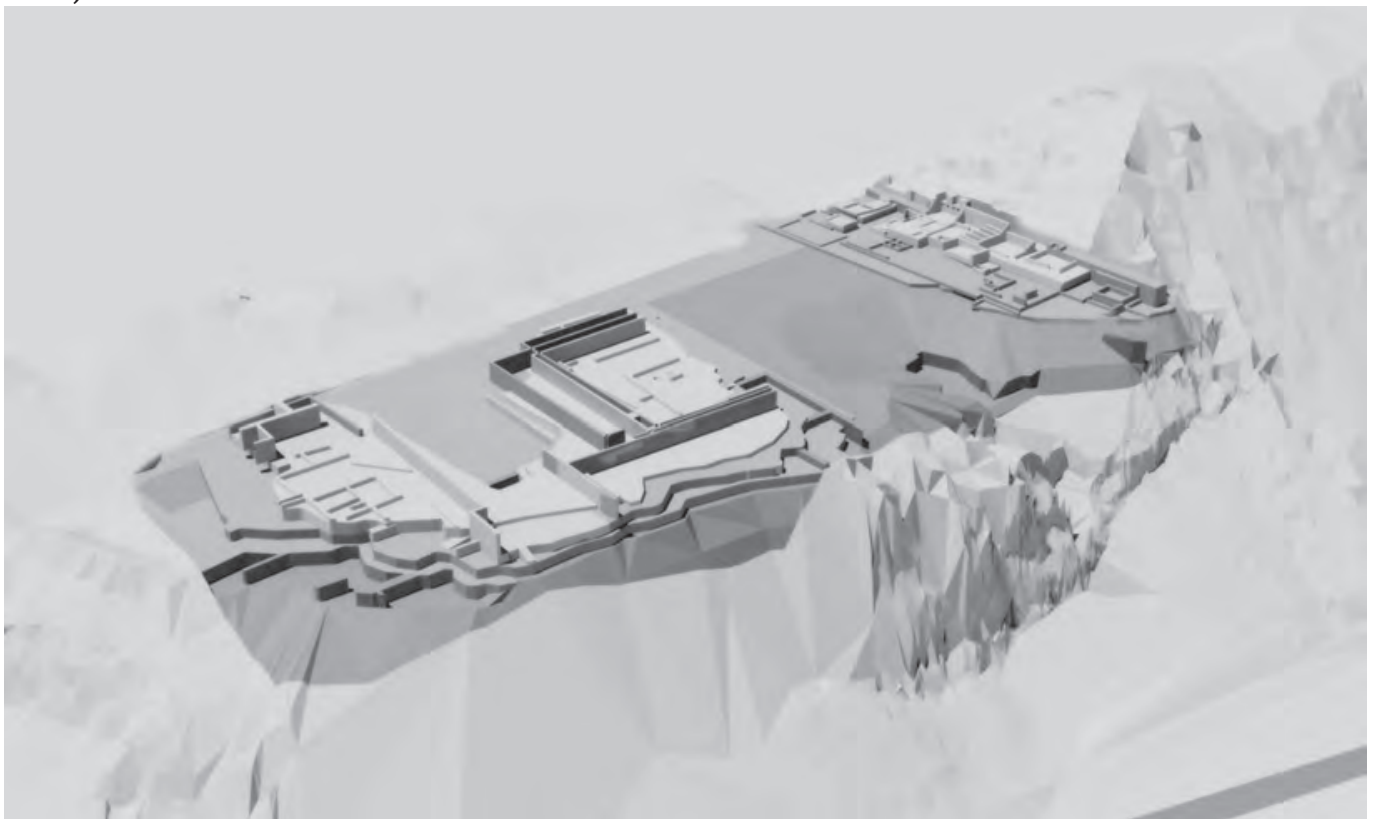

Figura 11. Reconstrucción hipotética de sección 2. 
Fase ocupación reocupando y remodelando la última fase constructiva moche (Fig. 12). Se rompe la arquitectura precedente intruyendo construcciones de quincha ${ }^{18} \mathrm{y}$ se destaca un incremento en importancia de ciertos depósitos para el nuevo piso (P2). Por ejemplo, la UEA 20a con hornacinas (fig. 13), que es muy posible que lo que se haya guardado o almacenado ahí, debió ser de lo más importante para la realización de sus reuniones. Esta última fase presentó la siguiente remodelación (Fig. 10f):

Primera remodelación: Se construyen muros de adobes sobre los muros de quincha, se sella el P2 por el nuevo piso (P1) y se intruyen fogones en los pisos de ocupación Moche con fines domésticos. (Fig. 14)

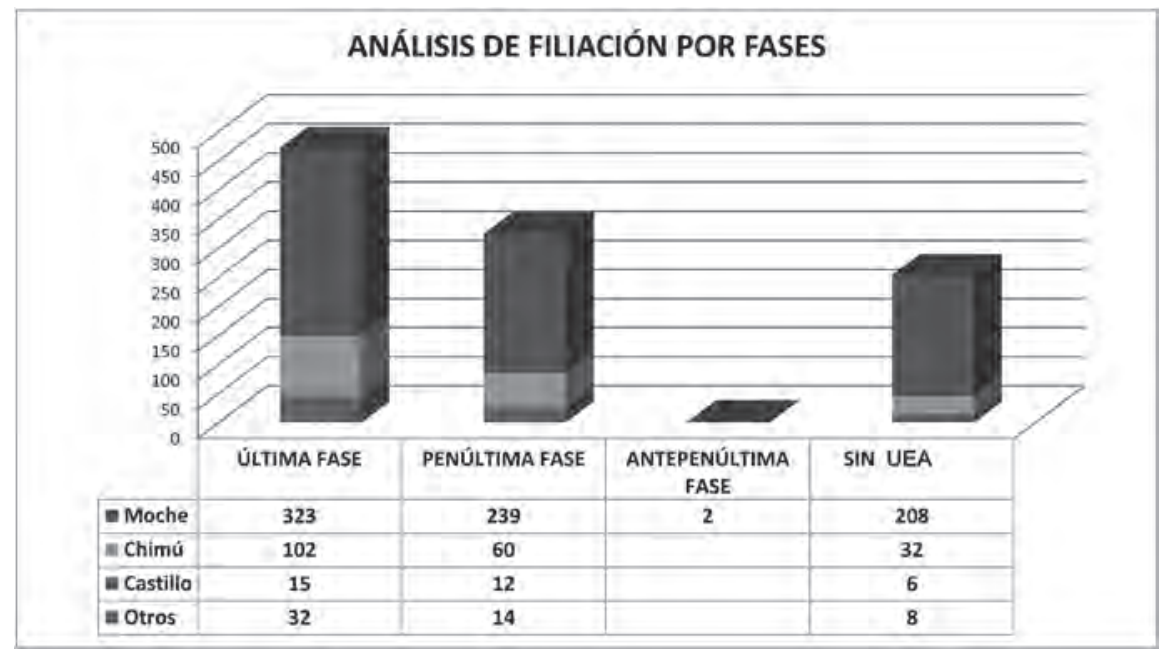

Figura 12. Fragmentos analizados según su filiación por fases.

\section{DEFINIENDO SU COMPLEJIDAD COMO PALACIO-TEMPLO}

El definir los atributos formales de esta arquitectura del poder, para caracterizar a qué tipo particular de edificio correspondería, fue uno de los objetivos principales que nos planteamos al inicio de la investigación. En función de esta perspectiva y valiéndonos del dato arqueológico e iconográfico ${ }^{19}$ trataremos de definir su espacio físico y la funcionalidad ligada al sitio de Huaca del Sol. No obstante, antes de seguir adelante ypara los fines de nuestro argumento, es pertinente distinguirla semántica ${ }^{20} \mathrm{a}$ utilizar para hacer frente al dilema de su identificación.Entiéndase: templo, palacio.

El templo, en sus inicios fue la morada de Dios, el axis del mundo, espacio sagrado que permite comunicar los planos cósmicos. Luego el templo es capturado por las élites en los estados antiguos para legitimar su poder y construir ese poder a partir de ceremoniales y rituales públicos como sistema de propaganda política.

18 Tal como aparece en la documentación arqueológica la quincha con armazón de cañas se usa para edificar construcciones delgadas de función doméstica, son construcciones temporales encima la arquitectura monumental

19 El dato arqueológico provee los espacios físicos a los que las imágenes solamente aluden, mientras que las imágenes iconográficas llenan los espacios físicos vacíos con actividades y actores ( $c f$. Harrison y Andrews, 2004: 124).

20 La semántica trata de conceptos e ideas por usar y eventualmente construir concepciones del mundo (Corsi et al. 1996:144). 


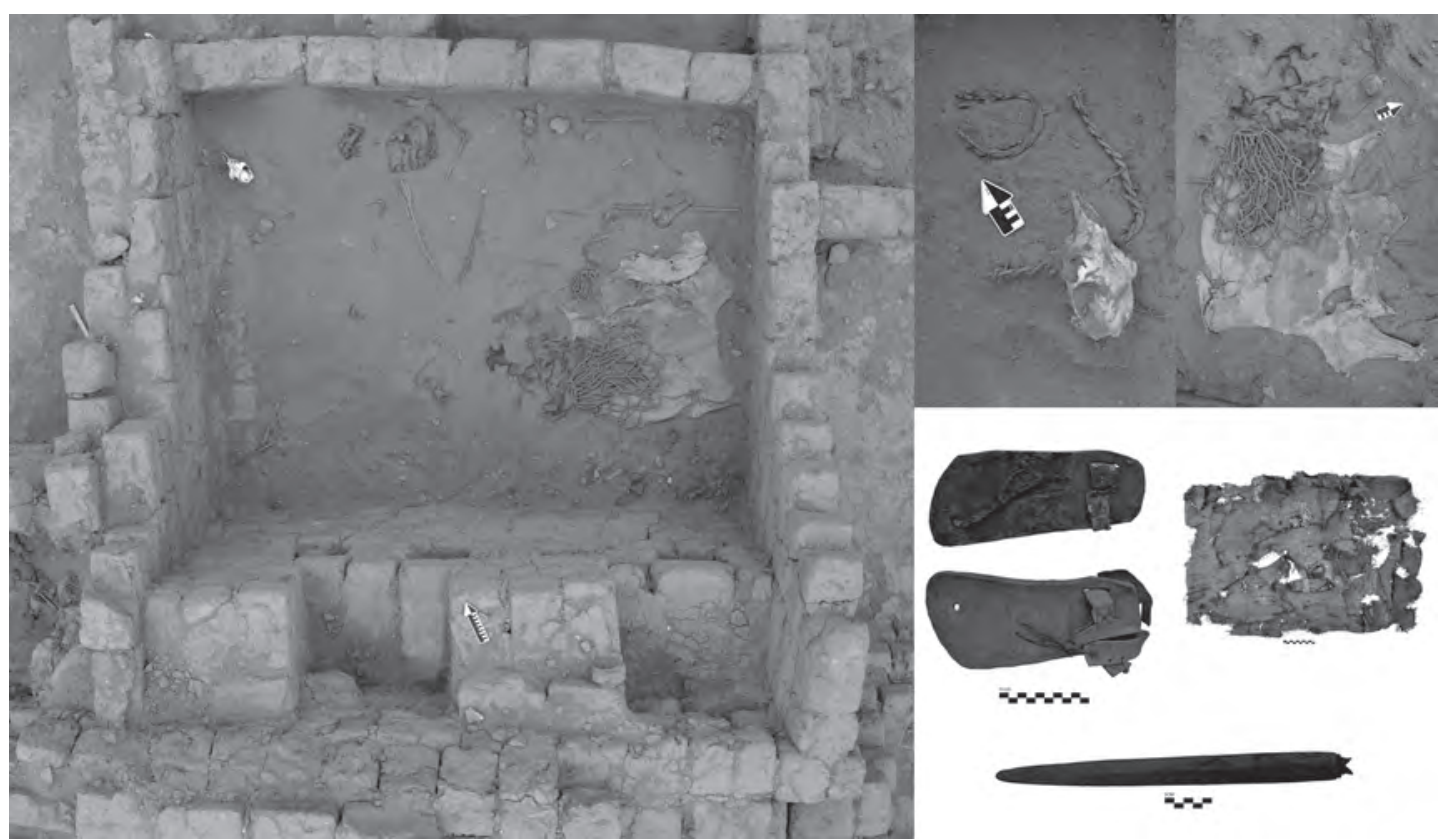

Figura 13. UEA-20a con evidencia postMoche.
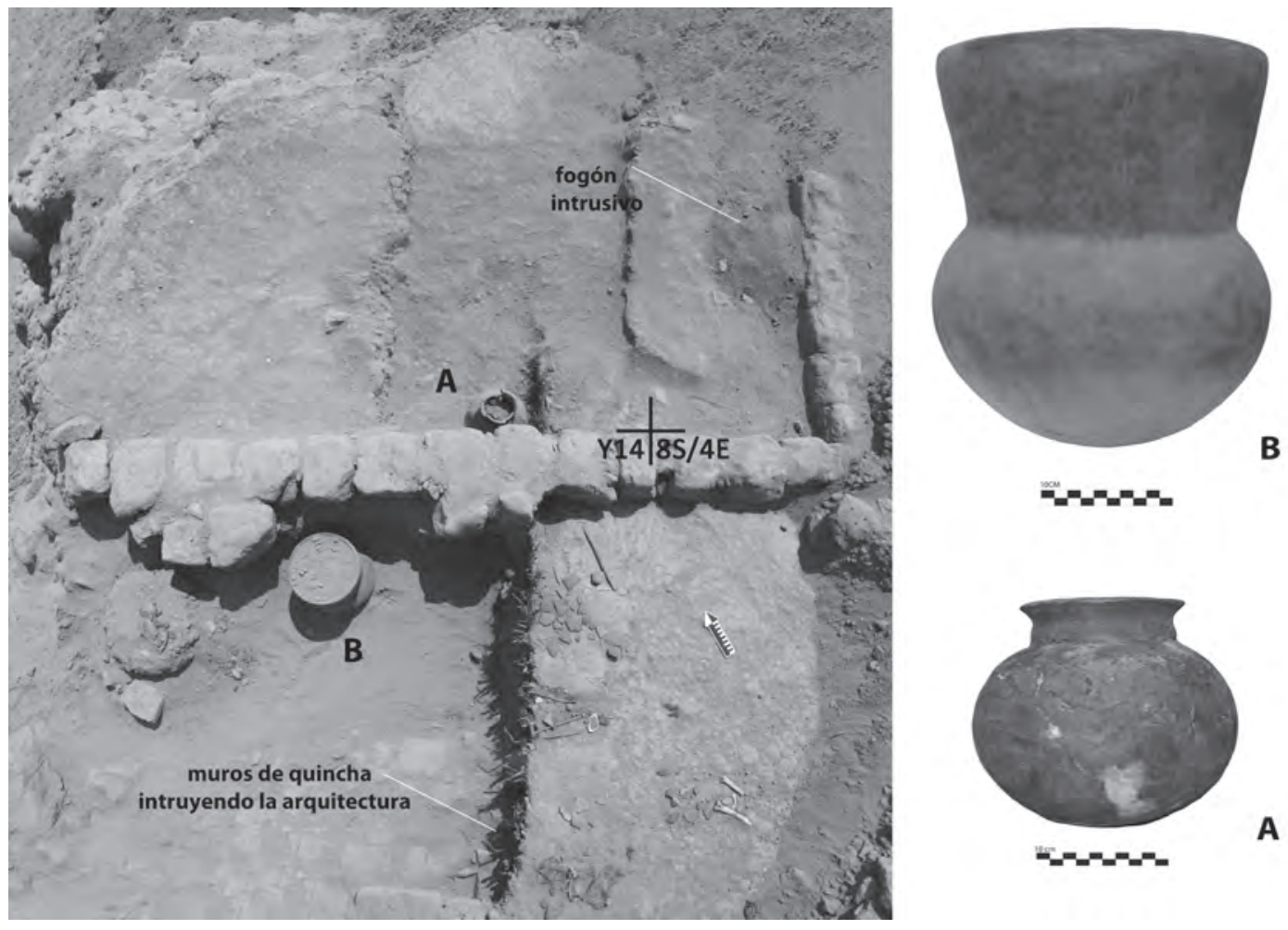

B

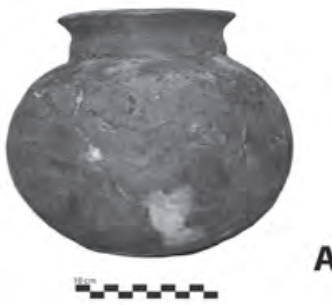

Figura 14. Primera remodelación de última fase en la sección 2 de Huaca del Sol. 
El palacio es la residencia del rey, desde donde ejerce su gobierno rodeado de una corte. En el área andina la definición de palacio es a partir de las crónicas ${ }^{21}$, y en las descripciones del dato arqueológico se ha tratado de adecuar a dichas definiciones.

Bajo esta precisa asimetrización ${ }^{22}$, que nos permite definir de antemano las características básicas de estas estructuras arquitectónicas, derivaremos una serie de indicadores arqueológicos que nos permitan precisar sus atribuciones diferenciales dentro del complejo arqueológico.

\section{Investigaciones en la Sección 2 de Huaca del Sol}

A partir de la evaluación física, espacial y funcional de la sección 2 de Huaca del Sol, erigida sobre la base de sus operaciones comunicativas y de su recursividad, entendemos que su función ${ }^{23}$ durante el primer periodo (100-600 d.c.), tiempo en el cual sólo presentaba sus secciones 2 y 3, fue la de una residencia, compatible con actividades de carácter doméstico-residencial, pues desde allí no se ejercía el poder, sino a partir del templo. Esta actividad se ha determinado a raíz de la diferencia elemento cerámico/relación, puesto que se observó vasijas que se encuentran asociadas a actividades de preparación y consumo de alimentos (Figs. 15 y 16).

Luego, tenemos que a consecuencia de un proceso autopoiético definido en su cierre operativo, la función que inicialmente desempeñaba como residencia del señor Moche con fines doméstico-residencial; se vió incrementada tiempo después (600-850 d.C.) con actividades político-administrativas propias de un palacio. No obstante, refuerza la hipótesis de que se puede incorporar actividades domésticas dentro del mismo palacio (Canziani 2003); que a decir de Luhmann (2006) se define como un reentry ${ }^{24}$.

Esta segunda actividad se manifestó en la sección 2, a causa de dos diferencias: elemento arquitectónico/relación y elemento cerámico/relación.

La primera diferencia, es definida por la ampliación a cuatro cuerpos del edificio y la concentración de depósitos ubicados en el extremo sur de la sección, que se repiten e incrementan en todos los pisos de ocupación; con muros burdos y espacios interiores reducidos que hacen sospechar que la vida cotidiana tenía lugar fuera de estas unidades estructurales arquitectónicas (Fig. 4). Sin embargo, pisos y paredes fueron enlucidos, lo cual demuestra su preocupación por mantener las condiciones ambientales requeridas para la conservación de sus recursos. Añadese, además, la construcción de una terraza donde se ubicó una audiencia ${ }^{25}$ con dos banquetas paralelas (Tufinio et al. 2012), que debió ser el lugar político más público en términos de visibilidad y en donde se habrían realizado reunidos con señores de menor rango representantes de las diferentes parcialidades sometidas al dominio moche y que sostenían la fuerza y representación política, participaban de estas reuniones precedido por el personaje principal instalado en un trono ${ }^{26}$. Apoyándonos en la diferencia elemento iconográfico ${ }^{27}$ /relación del arte Moche (Hocquenghen et al. 1987, Donnan 1975), tenemos dos temas que si bien

21 Véase la descripción de un palacio inca hecha por Murúa (1687 (1611-16): libro 2,cap. 2, 345-348)

22 La asimetrización es introducir referencias para identificar un acontecimiento, como es el caso:»A es A sólo si...», donde la condición» sólo si...» (Corsi et al. 1996:27).

23 La sistemática de Luhmann (2006) presenta un modelo funcional-estructuralista, donde el concepto de función tiene mayor relevancia que el de estructura. En este marco, sostiene que los sistemas sociales reducen la complejidad valiéndose de estructuras versátiles.

24 Permite distinguir una diferencia dentro de otra diferencia.

25 El término «audiencia» es utilizado en este escrito para hacer referencia a la asociación de una terraza que domina un gran patio al interior del palacio, por lo que no debe confundirse con aquel que hace referencia a las estructuras en forma de $\mathrm{U}$ de las famosas ciudadelas de Chan Chan. 


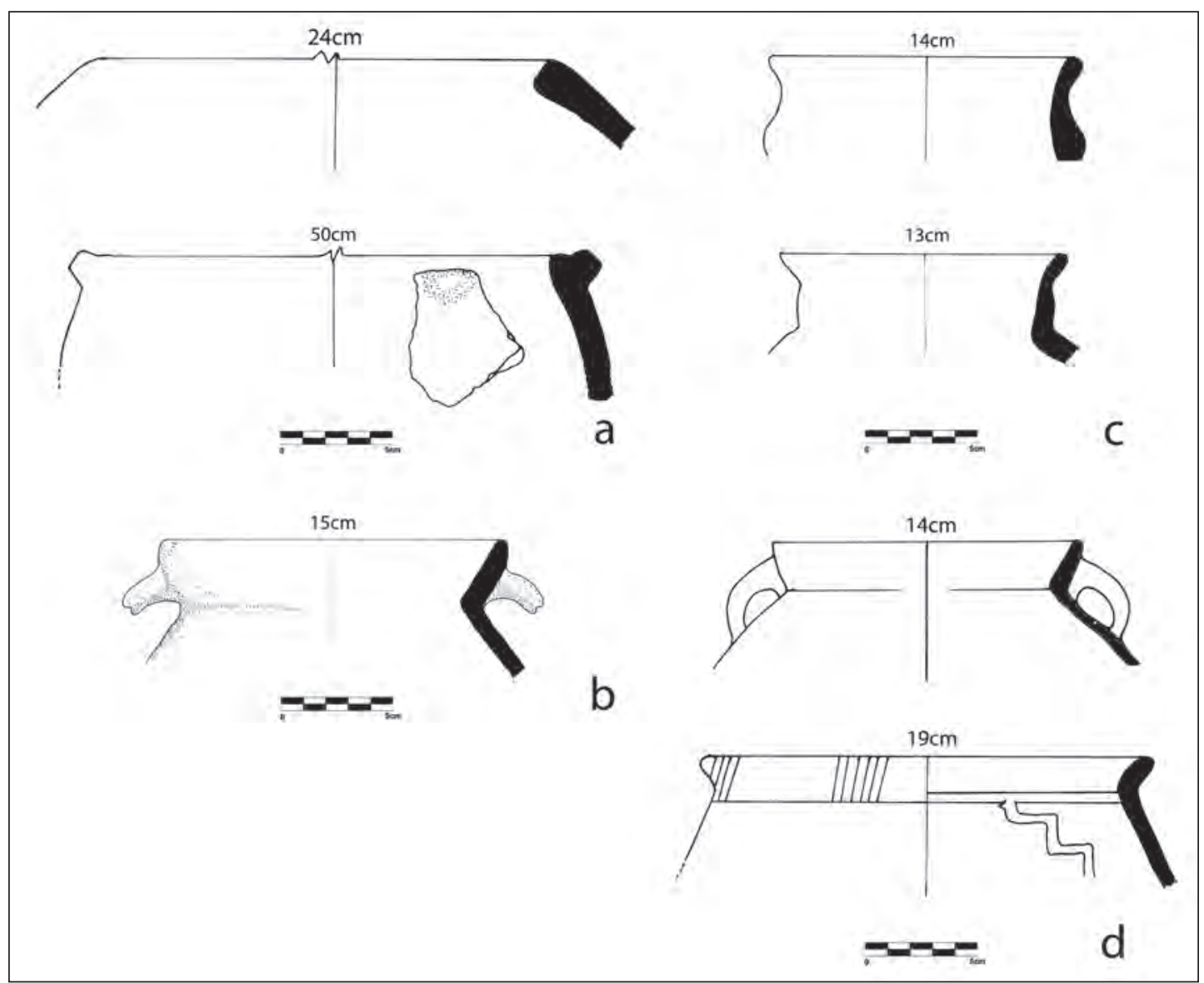

Figura 15. Ollas: a) sin cuello; b) convexo; c) evertido; d) divergente.

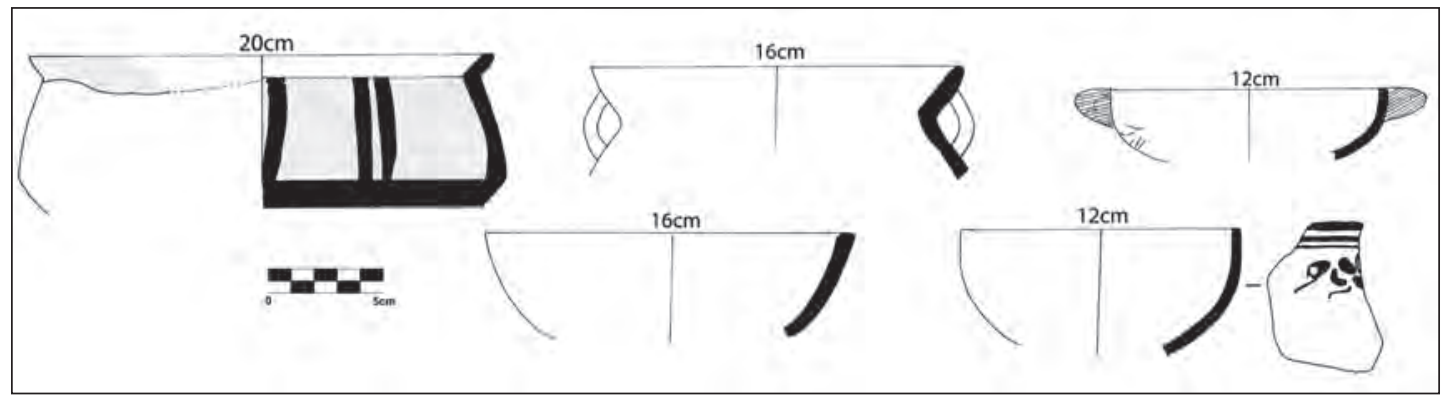

Figura 16. Cuencos

son simplemente suposiciones sin mayor consistencia documental podrían explicar las actividades acontecidas para este espacio: El primero, está referido al ritual de entrega de ofrendas de conchas Spondylus y Conus traídos de la zona ecuatorial para ser mostrados al gran señor Moche apostado sobre el trono como símbolo del poder sobre el agua o como simple comercio de bienes suntuarios que luego se sacraliza en el templo; y el segundo, sería el tema de la consagración de la sangre en una copa conteniendo la sangre de los prisioneros entregada por un sacerdote al gran señor Moche como símbolo del poder sobre la vida. 
En tanto, tenemos que la segunda diferencia, es debido a la asociación de los depósitos con vasijas que sirvieron para la conservación de los alimentos, pues predominan los cántaros y tinajas (fig. $17 \mathrm{y}$ 18). Esta iniciativa de almacenar el excedente de producción fue una estrategia ${ }^{28}$ definida en su clausura operativa para reducir el riesgo y sostener al sistema político-económico ante la crisis sociopolítica que atravesaba dicha sociedad (Seoane et al. 2010); la misma que habría estado controlado desde el ambiente 17, a decir de su ubicación estratégica al interior del área de depósitos.

De otro lado, con base en las líneas de evidencia usadas en la investigación, se puede asumir que la vida alrededor del gobernante dentro de este edificio era lujosa, en comparación con estratos más bajos, pero no exuberante. Seguramente no eran «hogares opulentos» parecidos a los palacios occidentales, tal como lo sugiere Houston ${ }^{29}$ (2004).

Bajo estas consideraciones, se concluye en tres aspectos: (1) definir a Huaca del Sol como una estructura arquitectónica que combinó funciones domésticas y públicas, con espacios funcionalmente diferenciados que incluyó instalaciones de almacenamiento, espacios para ceremonias y rituales; y espacios de servicios. Dicho de otro modo, fue un centro de acopio, transformación y distribución de los recursos más importantes de la comunidad y referente fundamental de su idiosincrasia social. Aquí las ofrendas eran insumos que se convertían en bienes suntuarios como tejidos, cerámica o metales o bien en comidas y bebidas, los que eran a su vez redistribuidos y consumidos entre los diferentes estamentos de la sociedad prehispánica de la costa central como de otras partes del litoral, especialmente la costa norte (Ramirez 2001); (2) proponer como hipótesis de estudio que el poder político en tiempos de la instauración de un nuevo modelo de organización socio-política tipo secular, debió estar centrado en Huaca del Sol y en la figura de un gran señor, cumpliendo así un rol activo dentro del complejo, puesto que las actividades realizadas en el Templo Nuevo habrían sido la materialización de sus decisiones ${ }^{30}$; (3) Observando la configuración arquitectónica de Huaca del Sol y la similitud con los palacios lambayecanos, es lícito plantearse una tradición compartida en la costa norte entre Lambayeque y Chimú (Wester et al 2010).

\section{IRRITACIONES DEL SISTEMA MochicA TEOCRÁTICo}

A través del estudio de la política secular presidida desde Huaca del Sol al final de la ocupación Moche, aspiramos comprender su capacidad operativa frente a la complejidad social. Para tal fin, creemos necesario identificar, entender y conceptualizar las interrelaciones entre actores, estructuras y pro-

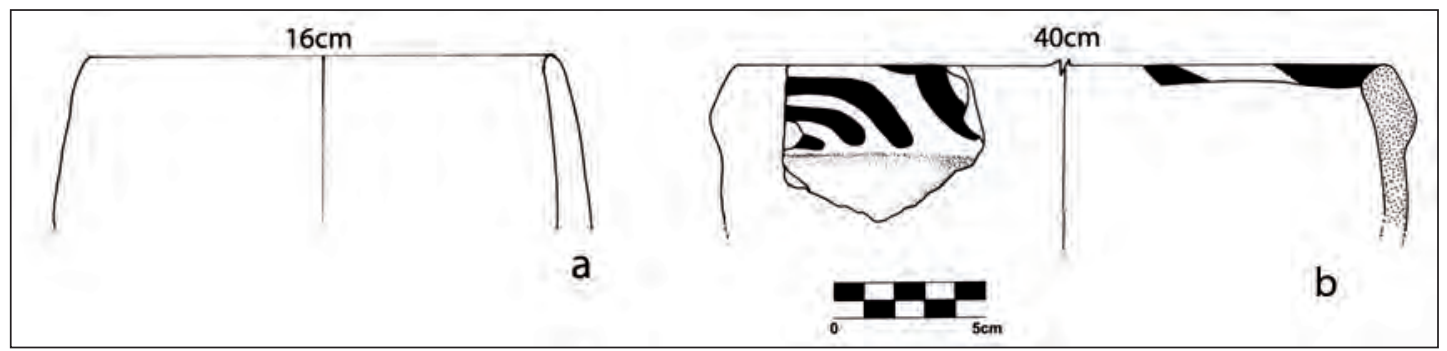

Figura 17. Tinajas: a) tinaja de borde simple; b) tinaja de borde reforzado

28 Al respecto, Netherly (1990) registra que en la época Chimú el almacenamiento fue probablemente descentralizado incluso hasta en niveles de organización bastante bajos como un mecanismo de reducción de riesgos.

29 Houston, Stephen D. 2004 «The Acrópolis of Piedras Negras. Portrait of a Court System», Courtly Art of the Ancient Maya, pp. 271-276, M. E. Miller y S. Martin. San Francisco: Thames and Hudson/Fine Arts Museum of San Francisco.

30 Bawden (1994) considera al templo como sancionador moral y catalizador de conflictos, separados del poder político que debió estar asentado en el palacio de Huaca del Sol. 


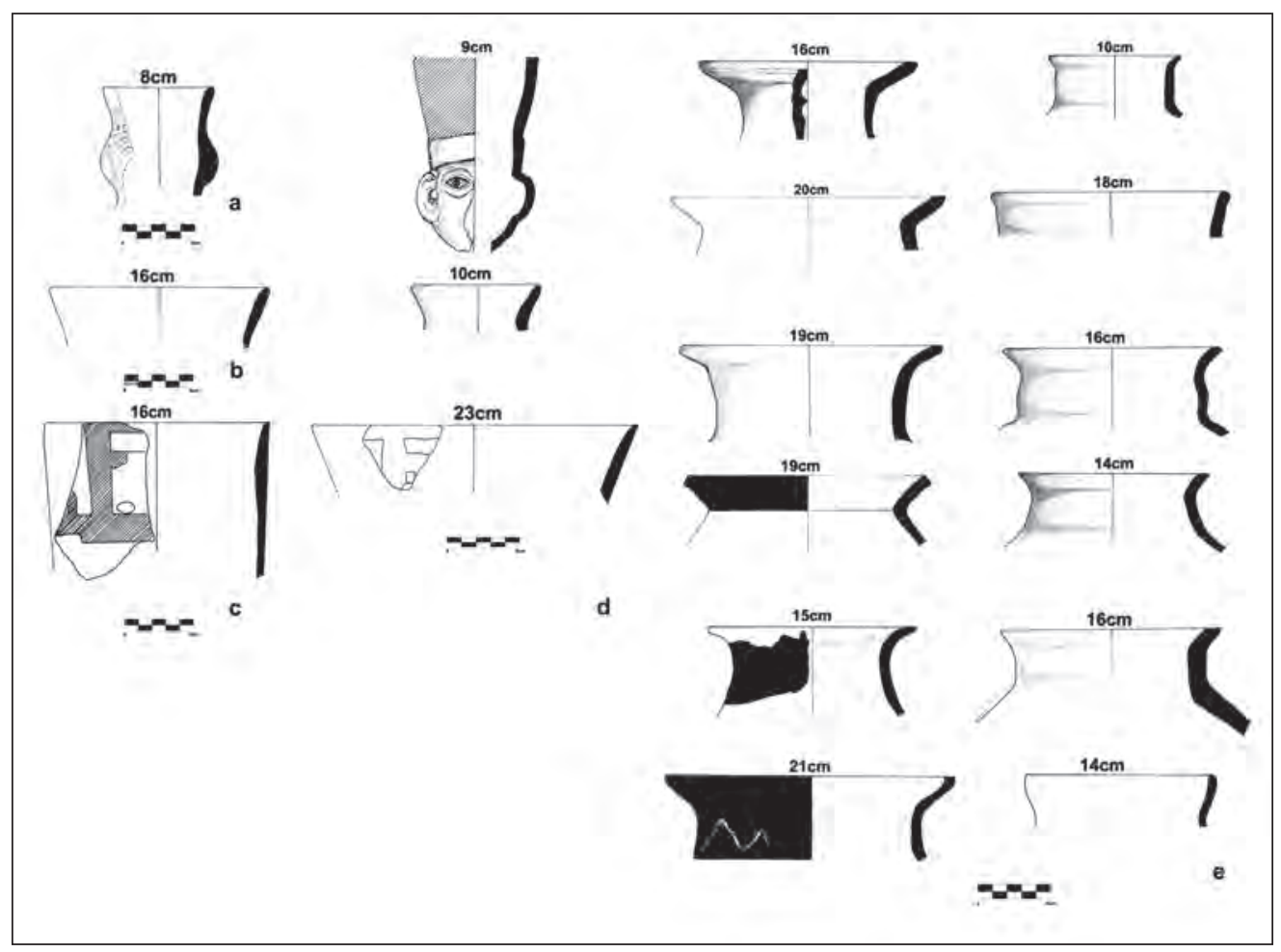

Figura 18. Cántaros: a) evertido; b) convexo; c) recto; d) expandido; e) diverso.

cesos acontecidos en la dinámica socio-política y económica del complejo Huacas de Moche. Así, en lo que sigue, dividimos nuestro esquema de trabajo en los dos grandes periodos comprendidos para el acontecer Moche en este complejo arqueológico.

\section{PRIMER PERIODO (100-600 d.C.)}

El complejo Huacas de Moche con sus dos estructuras monumentales ${ }^{31}$ y su compleja red urbana se consolidó como el centro del gobierno para este periodo (Donnan y Castillo 1991; Shimada 1988). Esta diferenciacióncentro/periferia y estratigráfica muestra dos clases sociales fuertemente arraigada por aquellos tiempos ${ }^{32}$, los mismos que se caracterizaban por dos criterios fundamentales: alta abstracción [ideología exclusiva de los gobernantes (Bawden 1994) y rígidos valores religiosos (Gayoso 2004)]; y alta especificidad [estratos sociales que tienen bien claro sus roles en la sociedad (Quilcate 2003)]. No obstante, después de dominar por más de 600 años la costa nor central y norte del Perú, acontecieron diversas irritaciones ${ }^{33}$

31 El viejo templo de la Huaca de la Luna con su discurso iconográfico de poder tendría la función exclusiva de Templo (Uceda 2010) y Huaca del Sol (sección 2 y 3) sería el palacio del señor Moche acorde a la propuesta definida en el capítulo anterior.

32 Una alta o citadina, que desempeña roles dirigenciales: oficiantes y sacrificadores y otra baja o rural: agricultores, ganaderos o pescadores (Quilcate 2003)

33 Desde la óptica de Luhmann las causas que deterioran un sistema son entendidas como irritaciones, que son situaciones de desorganización, desorden y conmoción que impiden el funcionamiento normal de un sistema y ponen en peligro su organización. Este concepto, a su vez, presupone una diferencia entre una secuencia operacional normal y un estado de cosas no claras e indecisas (Luhmann 2006:626,628). 
en su sistema; sobre las cuales se han tejido propuestas que se reducen a tres factores ${ }^{34}$ : Relaciones con vecinos hostiles, en el cual los Moche en sus últimos momentos habrían enfrentado una invasión serrana (Lumbreras 1969); cambios climáticos, con presencia de lluvias intensas y sequías que simultáneamente habrían azotado la costa norte (Moseley y Feldman 1982; Shimada et al. 1991); y problemas de la propia estructura interna del sistema, que se traduce en las contradicciones de su estructura sociopolítica, lo cual habría generado divisiones que determinarían una revolución social (Bawden 1982, 1995; Castillo 2000, 2001; Shimada et al. 1991; Rucabado y Castillo 2003; Uceda 2008). Haciendo hincapié en este último factor, diremos que al estar alineados en un pensamiento sistémico, el colapso también lo apreciamos dentro del propio sistema y no tanto por una dependencia de factores externos; sin embargo, se valora qué elementos pudieron ser críticos en un contexto determinado. De modo, que los efectos del acoplamiento estructural entre sistema y entorno no pueden determinar el devenir de un sistema, dado que cada determinación sólo puede producirse en el cierre recursivo de sus propias operaciones (comunicación). Así, el sistema tiene la doble posibilidad de reaccionar; ya sea mediante un feedback negativo (eliminando la diferencia surgida por la irritación) o un feedback positivo (reforzando la desviación). Al respecto, es obvio que el sentido que tomó la decisión del poder político Moche asentado en el viejo templo de la Huaca de la Luna fue hacia un feedback positivo. Siguiendo las ideas de Luhmann (2006), esto habría acontecido debido a que los dirigentes del sistema se alejaron demasiado de los rangos inferiores, quienes al no tener una comunicación influyente en la complejidad del sistema y percibir la ineficiencia de las funciones de las estructuras de poder, formaron movimientos de protesta $a^{35}$ que provocaron problemas estructurales que finalizaron con el abandono de su política teocrática ${ }^{36}$.

\section{SEGUNDO PERIODO (600-900 d.C.)}

El abandono del modelo teocrático significó la reestructuración de toda su organización. La tendencia fue hacia una política secular de mayor complejidad regida por un gran señor Moche asentado en la Huaca del Sol. Su manejo debió ser de colaboración y permanente reciprocidad y no de imposición y control como sucedió en el periodo precedente (Uceda 2010). Dentro de este contexto, vemos que su política se autorrefiere por la autopoiesis en su estructura arquitectónica-iconográfica ${ }^{37}$,

34 Apoyándonos en la lista que hiciera Jared Diamond (2006) de cinco probables causas del colapso de las sociedades, vemos que en la sociedad Moche se presenta tres de éstas.

35 Sistema autopoiético de tipo propio que estuvo dirigido a cumplir dos metas específicas: igualdad interna y equilibrio externo. Es una forma para que la sociedad pueda observarse a sí misma; es una resistencia contra algo; ésa es su manera de construir realidad (Luhmann 2006)

36 Uceda (2004:232) al respecto menciona: «...en una sociedad altamente teocrática, donde los dirigentes asumieron el rol de las mismas divinidades, no es ajeno pensar que esta acumulación de poder llevó a crear mayores distancias entre las diferentes regiones, así como entre la misma población. En esta sociedad en conflicto, la presencia de una crisis que los dioses no pueden resolver, debe tener como resultado el aumento paulatino de su desprestigio...».

37 Con la construcción de Huaca del Sol para su penúltima fase; y del Templo Nuevo menos sacralizado, donde lo más sintomático fue la desaparición del personaje del dios de la montaña por nuevos iconos que estarían ligados a los proceso convulsionados de esta época (Uceda et al 2011); y remodelaciones en el diseño urbano donde se establecieron residenciales multifuncionales compuestos por conjuntos arquitectónicos destinadosa funciones específicas de control de la producción, preparación de alimentos, talleres y otros. 
económica ${ }^{38}$, social ${ }^{39}$ e ideológica.Esta última, se observa de manera más elocuente dentro del complejo como un reentry ${ }^{40}$ producto de la relación sistema/entorno; a decir de la presencia recurrente y distintiva de cerámica con rasgos foráneos, provenientes de sociedades emergentes de la costa central y sierra sur. Ésta es una producción local ${ }^{41}$ que viene siendo registrada en las dos temporadas de excavación en la sección 2 de Huaca del Sol (Tufinio et al. 2012-13), donde se ha recuperado una muestra reducida de tiestos, que se asemejan al grupo II y III de San José de Moro ${ }^{42}$. Otras áreas con estas evidencias tenemos en la Plaza 1 del templo viejo (Orbegoso et al. 2012) y el noroeste del núcleo urbano (Zavaleta et al 2012).

Esta influencia externa ha sido entendida como una estrategia de los dirigentes por sustentar su legitimidad dentro del contexto de crisis $^{43}$ (Castillo 2003). Sin embargo, como hacen constar los estudiosos sobre el tema, esta estrategia dirigencial en los valles nucleares de Moche y Chicama no tuvo el arraigo que se esperaba, debido a que la ideología estatal Mochica se encontraba más enraizada y por lo tanto menos susceptible y permeable a la influencia foránea, especialmente serranos, con el que habrían tenido fluido contacto comercial.

Por lo dicho con anterioridad, se subyacen tres procesos acoplados que son fundamentales para entender estos hechos: Como causa primaria, se denota un proceso de des diferenciación ${ }^{44}$ del sistema político secular con respecto al sistema económico e ideológico; lo cual impulso tanto un proceso de inclusión, donde se tomaron en cuenta socialmente a los rangos inferiores otorgándoles beneficios que en realidad no eran financiables; como un proceso de no-irritabilidad, en donde se insistía en los principios éticos o en los valores ${ }^{45}$ irrenunciables del propio sistema. De ahí que, que se degeneró la capacidad del sistema por incrementar su propia complejidad conduciéndolo al colapso.

En resumen, hemos dicho que la crisis del complejo Huacas de Moche como situación compleja y multicausal se configuró en el plano operativo (clausura operacional) donde salió a relucir problemas de comunicación y no en el plano del entorno. Así, la crisis se fue modulando a partir de un mal funcionamiento de una unidad del sistema que llevó al mal funcionamiento de otras (acoplamiento estructural). En primera instancia, se produjeron desajustes en los aspectos políticos, debido a que excedieron sus propias capacidades de poder sin dar una respuesta eficiente a los problemas con su entorno. Esto llevó a una crisis en la estructura económica ${ }^{46}$, que careció de dinamismo para soportarlo, convirtien-

38 Manifiesto en razón al incremento del poder económico del estamento civil, que se evidenció por el aumento de los lugares de almacenamiento, de la cerámica de línea fina y de la presencia de objetos rituales en las residencias; en tanto en los aspectos sociales se dio una mayor jerarquización, debido a que los señores de la elite urbana moche empiezan a controlar especialistas, organizar actividades ceremoniales y rituales dentro de sus residencias. Sería este grupo de señores de la elite urbana quienes dieron sostén y máximo poder al señor asentado en la Huaca del Sol (Uceda 2010).

39 Se dió una mayor jerarquización, debido a que los señores de la elite urbana moche empiezan a controlar especialistas, organizar actividades ceremoniales y rituales dentro de sus residencias. Sería este grupo de señores de la elite urbana quienes dieron sostén y máximo poder al señor asentado en la Huaca del Sol (Uceda 2010).

40 La categoría reentry nos permite distinguir entre lo auténtico/foráneo.

41 No se importaba cerámica foránea como sí había ocurrido en el sitio de San José de Moro.

42 Semejanza con estilo Wari del Horizonte Medio. Para mayores alcances véase el informe técnico 2007 para el sitio.

43 En Mesopotamia por ejemplo, tenemos el caso de la élite Aslantepe, donde se sugiere que ésta habría ganado prestigio y legitimidad a través de la relación ideológica con Uruk. (Baltali s/f)

44 Entendiéndose por des diferenciación a la falta de cercanía de una realidad en crisis sistémica

45 Según Diamond (2006), los valores religiosos suelen ser convicciones especialmente profundas y por tanto origen frecuente de una conducta desastrosa.

46 Dillehay (2001:260) menciona que «cuando las sociedades «colapsan» es su estructura política y su economía las que acaban, no la población a la larga». 
dose en una carga permanente que hizo insostenible la estructura social e ideológico.Tras esta situación, se dieron movilizaciones contra el orden político que llevó en última instancia a su reforma con una tendencia secular con sede en el sitio de Huaca del Sol. Sin embargo, como se indicó líneas arriba, estos cambios no tuvieron éxito debido al proceso conjunto de des diferenciación, inclusión y no-irritabilidad que finalmente determinaron el colapso ${ }^{47}$ sistemático de esta organización.

\title{
CONCLUSIÓN FINAL
}

La teoría de sistemas de Luhmann aplicado en nuestra disciplina es una alternativa coherente, viable e innovadora ${ }^{48}$; que reorienta nuestro pensamiento y concepción de interpretación del pasado, abriendo nuevas vías para la teoría y la investigación. De aquí, que nos permitió entender la complejidad interna de Huaca del Sol, definiendo sus contextos y percibiendo con claridad la naturaleza de sus relaciones internas y externas con su medio.

\section{Agradecimientos}

Al codirector del proyecto arqueológico Huacas del Sol y de la Luna, Dr. Santiago Uceda por sus críticas y sugerencias en el proceso de investigación y redacción del texto. Al Dr. Javier Torres Nafarrate, discípulo de Niklas Luhmann en la Universidad de Bielefield, por atender nuestras interrogantes vía email y por sus sabios consejos y sugerencias sobre la teoría utilizada. Finalmente, un especial agradecimiento al Lic. Ronny Vega por su ayuda técnica en el desarrollo de este artículo.

\section{BIBLIOGRAFÍA}

\author{
AMOZURRRUTIA, José \\ 2007 Sistemas Adaptativos para el Análisis Social: una aproximación desde la Socicocibernética. Disertación \\ Doctoral. Universidad de Zaragoza, España. \\ ALMUDENA, Hernando \\ 1992 «Enfoques teóricos en arqueología». SPAL 1:11-35. Madrid. \\ BALTALI, Sevil \\ s/f «Culture contact, cultural integration and difference. A case from Northern Mesopotamia». En: \\ Stanford Journal of Archaeology. Departament of Anthropology, Yeditepe University, Turkey. \\ BAWDEN, Garth \\ 1977 Galindo and the Nature of the Middle Horizon in Northern Coastal. Peru. Ph.D. dissertation.Department \\ of Anthropology, Harvard University. Cambridge, MA. \\ 1982 «Galindo: A study in cultural transition during the Middle Horizon». En: M. E. Moseley y K. Day \\ (eds.) Chan Chan: Andean Desert City: 285-320. Albuquerque: TheUniversity of New Mexico Press. \\ 1994 «La paradoja estructural: la cultura Moche como ideología política». En: S. Uceda y E. Mujica (eds.) \\ Moche: propuestas y perspectivas. Actas del Primer Coloquio sobre la Cultura Moche (Trujillo, 12 al 16 de \\ abril de 1993), Travaux del'Institute Français d'Etudes Andines 79: 389-412. Universidad de La Libertad, \\ Trujillo, IFEA y Asociación Peruana para el Fomento de las Ciencias Sociales. \\ 1995 «The structural paradox: Moche culture as political ideology». Latin American Antiquity 6 (3): 255- \\ 273. Washington, D.C., Society for American Archaeology. \\ 2001 «The symbols of late Moche social transformation». En: J. Pillsbury (ed.) Moche Art and Archaeology \\ in Ancient Peru: 285-305. Studies in the History of Art 63. Center for Advanced Studies in the Visual \\ Arts, Symposium Papers XL. Washington, D.C. National Galery of Art.
}

47 Según Diamond (2006) es un rasgo frecuente que las sociedades se derrumben rápidamente poco después de alcanzar la cima de su poder.

48 Reformula el estudio de las sociedades a partir de una descripción como totalidad y diferencia. 
BONNIER Elisabeth

1985 «Acerca del surgimiento de la arquitectura en la sierra andina». En: V. Rangel (comp. y ed.) Arquitectura y arqueología, pasado y futuro de la construcción en el Perú. CONCYTEC.

CAMPOS, María; Lucía MOLINA, David SALAS

2010 Teoría de los sistemas de Niklas Luhmann. Universidad de Costa Rica, Facultad de Derecho.

CARMONA, Gabriela

2006 Caracterización de las prendas textiles incas presentes ensitios arqueológicos tardíos del extremo norte de Chile. Memoria para optar al título profesional de ArqueólogaUniversidad de Chile, Facultad de Ciencias Sociales, Departamento de Antropología.

CANZIANI, José

1999 «Estado y ciudad: Revisión de la Teoria sobre la sociedad Moche». En: S. Uceda y E. Mujica (eds.) Moche: hacia el final del milenio. Actas del Segundo Coloquio sobre la Cultura Moche (Trujillo, 1 al 7 de agosto de 1999), T. II, pp. 287-311. Lima, Universidad Nacional de Trujillo y PUCP.

CASTILLO, Luis Jaime

2000 «La presencia Wari en San José de Moro». En: P. Kaulicke y W.H. Isbell (eds.) Huari y Tiwanaku: modelos vs. evidencias. Boletín de Arqueología PUCP 4: 143-179. Lima: PUCP.

2001 «The last of the Mochicas: A view from the Jequetepeque valley». En: J. Pillsbury (ed.) Moche Art and Archaeology in Ancient Peru, pp. 307-332. Studies in the History of Art 63.Center for Advanced Studies in the Visual Arts, Symposium Papers XL.Washington, D.C., National Galery of Art.

2003 «Los últimos Mochicas en Jequetepeque». En: S. Uceda y E. Mujica (eds.) Moche: hacia el final del milenio. Actas del Segundo Coloquio sobre la Cultura Moche (Trujillo, 1 al 7 de agosto de 1999) T. II, pp. 65-124. Lima, Universidad Nacional de Trujillo y PUCP.

2007 Programa Arqueológico San José de Moro, Temporada 2006, Edición Digital. L.J. Castillo (ed.) Lima: PUCP.

CASTILLO, Luis J. y Santiago UCEDA

2007 «Los Mochicas de la Costa Norte del Perú». En: H. Silverman y W. Isbell (eds.) Handbook of South American Archaeology, Chapter X, BlackwellPress.

CORSI, Giancarlo; Elena ESPOSITO; Claudio BARALDI

1996 Glosario sobre la teoría social de Niklas Luhmann. Universidad Iberoamericana.Ed. Francoangeli.

CHAPDELAINE, Claude

1998 «Excavaciones en la zona urbana de Moche durante 1996». En: S. Uceda, E. Mujica y R. Morales (eds.) Investigaciones en la Huaca de la Luna 1996, pp. 85-115. Trujillo, Facultad de Ciencias Sociales de la Universidad Nacional de La Libertad.

DIAMOND, Jared

2006 Colapso: Por qué unas sociedades perduran y otras desaparecen. Edición en castellano para todo el mundo. Ricardo García Pérez, por la traducción Printed in Spain. Barcelona.

DILLEHAY, Tom D.

2001 «Town and country in late Moche times: A view from two Northern valleys». En: J. Pillsbury (ed.) Moche Art and Archaeology in Ancient Peru, pp. 259-283. Washington D.C.: National Galery of Art.

DONNAN, Christopher B.

1975 «The tematic approach to Moche iconography». Journal of Latin American Lore 1 (2): 147-162, Los Angeles: Latin American Center, Universidad of California.

DONNAN, Christopher B. y Luis Jaime CASTILLO

1992 «Finding the tomb of a Moche priestess». Archaeology 6 (45): 38-42. New York: The Archaeological Institute of America.

GALLARDO, Ruth y Jorge NARRO

1992 Revisión de la Arquitectura de la Huaca del Sol en la Sección 2. Informe de prácticas pre profesionales (Tesina). Trujillo, Escuela de Arqueología, Facultad de Ciencias Sociales, Universidad Nacional de Trujillo. 
GAYOSO, Henry

2004 Cronología y dinámica ocupacional de Ciudadela-Cerro Pampa de Faclo. Un sitio Mochica Tardío «A» del valle bajo del Jequetepeque. Trujillo: Universidad Nacional de Trujillo-Facultad de Ciencias SocialesEscuela de Arqueología.

HARRIS, Edward C

1991 Principios de Estratigrafía Arqueológica. Barcelona: Editorial Crítica.

HASTINGS, C. Mansfield y M. Edward MOSELEY

1975 «The adobes of Huaca del Sol and Huaca de la Luna». American Antiquity 40 (2):196-203. Washington, D.C.: Society for American Archaeology.

HERRERA, Berta y Carlos RAMÍREZ

1992 Secuencia constructiva de la sección 3 de la Huaca del Sol. valle de Moche. Informe de prácticas preprofesionales (Tesina). Trujillo: Universidad Nacional de Trujillo; Facultad de Ciencias Sociales, Escuela de Arqueología.

HERRERA, Bertha y Claude CHAUCHAT

2003 «La presencia moche temprano en la sección 1 de la Huaca del Sol, valle de Moche». En: S. Uceda y E. Mujica (eds.) Moche: hacia el final del milenio. Actas del Segundo Coloquio sobre la Cultura Moche (Trujillo, 1 al 7 de agosto de 1999), Tomo I, pp. 189-216.Universidad Nacional de Trujillo y PUCP.

HOCQUENGHEM, Annie Marie y Luc ORTLIEB.

1987 Iconografía Mochica. Lima: PCUP.

HOUSTON, Stephen D.

2004 «The Acrópolis of Piedras Negras. Portrait of a Court System», En: Courtly Art of the Ancient Maya, pp. 271-276, M. E. Miller y S. Martin. San Francisco: Thames and Hudson/Fine Arts Museum of San Francisco.

IZUZQUIZA, I.

1990 La sociedad sin hombres. Niklas Luhmann o la teoría como escándalo. Barcelona: Anthropos.

JOHNSON, Matthew

2000 Teoría arqueológica. Una introducción. Barcelona: Editorial Ariel.

LARCO HOYLE, Rafael

1948 Cronología arqueológica del norte del Perú. Biblioteca del Museo de Arqueología Rafael Larco Herrera, Hacienda Chiclín. Buenos Aires, Sociedad Geográfica Americana. [Reimpreso en: Arqueológicas 25. Lima, 2001].

LOCKARD, Greg

2005 Political Power and Economy at the Archaeological site of Galindo, Moche Valley, Peru. Ph.D. dissertation. Department of Anthropology, University of New Mexico, Albuquerque.

LÓPEZ, Julián

2002 «Hacia una nueva teoría de los sistemas organizativos». En:J. Gairín y P.Darder (coord.) Organización y gestión de centros educativos. pp. 292-92/292-112. Madrid: Praxis.

LUHMANN, Niklas

1991 Sistemas sociales. México: Universidad Iberoamericana, Alianza Editorial

1997 Organización y decisión. Autopoiesis, acción y entendimiento comunicativo. Barcelona: Universidad Iberoamericana y Anthropos.

1998 Sistemas sociales. Lineamientos para una teoría general. Barcelona: Universidad Iberoamericana y Anthropos.

2006a La sociedad de la Sociedad. Mexico: Herder.

2006b Sociología del Riesgo. México: Universidad iberoamericana.

LUMBRERAS, Luis G.

1969 De los pueblos, las culturas y las artes del antiguo Perú. Lima: Moncloa-Campodónico Editores.

MANSILLA, Dario y Javier NAFARRATE

2008 Introducción a la teoría de la sociedad de Niklas Luhmann. Universidad Iberoamericana A.C. Editorial Herder,S. de R.L. de C.V. 
MÈLICH, J. C

1996 «Introducción: el laberinto de la teoría de la sociedad». En: N. Luhmann (ed.) Teoría de la sociedady pedagogía. pp. 9-26. Barcelona: Paidós.

MOSELEY, Michael

1975 «Prehistoric Principles of Labor Organization in the Moche Valley, Peru». En: M.E. Moseley Source: American Antiquity, 2(40): 191-196. Society for American Archaeology.

NARVÁEZ, Alfredo

1996 «Las Pirámides de Túcume: Sector monumental». En: Túcume, pp.83-151. Colección Arte y tesoros del Perú. Lima: BCP.

NETHERLY, Patricia J,

1990 «Out of many, one: The organization of rule in the North Coast polities». En:M.E. Moseley y A.CordyCollins (eds.) The northern dynasties: Kingship and statecraft in Chimor. pp. 461-487. DumbartonOaks, Washington D.C.

ORBEGOZO, Milagros; Liz RAMÍREZ y Lucy CHUMBE

2012 «Excavaciones en el frontis norte en la plaza 1 de Huaca de la Luna». En: S. Uceda y R. Morales (eds.), Informe Técnico 2011, Proyecto Arqueológico Huaca de la Luna.pp. 129-214. Trujillo: Facultad de Ciencias Sociales de la Universidad Nacional de Trujillo.

PILLSBURY, Joanne

2008 «Los palacios del Chimor». En: K. Makowski (comp.) Señores de los reinos de la luna, pp. 201-218. BCP. Colección arte y tesoros del Perú.

POZORSKI, Shelia G.

1979 «Prehistoric diet and subsistence of the Moche Valley, Peru». WorldArchaeology 11(2): 163-184. London.

QUILCATE, Patricia

2003 Determinación de la estructura social Moche a partir del análisis de los contextos funerarios exhumados en el complejo Huacas de Moche. Tesis para optar el grado de maestro en ciencias sociales. Trujillo-Perú.

REDMAN, Charles

1990 Los orígenes de la civilización: Desde los primeros agricultores hasta la sociedad urbana en el Próximo Oriente. Traducido al español por Marina Picazo. Barcelona: Editorial Crítica.

RODRIGUEZ, Darío

2001 Gestión Organizacional. Elementos para su estudio. Segunda Edición. Ediciones Universidad Católica de Chile.

RUCABADO, Julio y Luis Jaime CASTILLO

2003 «El periodo Transicional en San José de Moro». En: S. Uceda y E. Mujica (eds.) Moche: hacia el final del milenio. Actas del Segundo Coloquio sobre la Cultura Moche (Trujillo, 1 al 7 de agosto de 1999) T. I, pp. 15-42. Universidad Nacional de Trujillo y PUCP.

SEOANE, Francisco; Víctor CAMPAÑA, Feren CASTILLO, Lucy CHUMBE, Patricia GAMBOA y Jermi MEJÍA

2010 «El Conjunto Arquitectónico № 42 y los bloques arquitectónicos en el Núcleo Urbano Moche». En: S. Uceda, E. Mujica y R. Morales (eds.) Informe Técnico del Proyecto Arqueológico Huaca de la Luna 2009, pp. 305 -395, Trujillo: Facultad de Ciencias Sociales, Universidad Nacional de Trujillo.

SOLÉ, Ricard

2009 Redes complejas. Del genoma a internet. Barcelona: Tusquels Editores, S-A. - Cesare Cantü.

SHIMADA, Izumi

1987 «Horizontal and vertical dimensions of prehistoric states in north Perú». En: J. Haas, S. Pozorski y T. Posorski (eds.) The Origins and Development of the Andean State, pp.130-144. Cambridge: Cambridge University Press.

1994 Pampa Grande and the Mochica Culture. University of TexasPress, Austin.

SHIMADA Izumi, Crystal B. SCHAAF, Loonie G. THOMPSON, y Ellen MOSLEY-THOMPSON

1991 «Implicaciones culturales de una gran sequía del siglo VI D.C. en los Andes peruanos». Boletín de Lima 13 (77): 33-56. Lima, Editorial Los Pinos. 
1991 «Cultural impacts of severe droughts in the prehispanic Andes: Application of a 1,500-year ice core precipitation record». WorldArchaeology 22 (3): 247-270. London.

TUFINIO, Moisés; Ronny VEGA, Carol ROJAS y Mirtha RIVERA

2012 «Excavaciones en la sección 2 de Huaca del Sol». En: S. Uceda y R. Morales (eds.) Informe Técnico 2011, Proyecto Arqueológico Huaca de la Luna. pp. 241-305. Trujillo: Facultad de Ciencias Sociales de la Universidad Nacional de Trujillo.

TRIGGER, Bruce G.

1992 Historia del pensamiento arqueológico. Barcelona: Editorial Crítica.

UCEDA, Santiago

1997 «Investigaciones en la Huaca de la Luna: a manera de introducción». En: S. Uceda, E. Mujica y R. Morales (eds.) Investigaciones en la Huaca de la Luna 1995, pp. 9-15. Trujillo: Facultad de Ciencias Sociales de la Universidad Nacional de La Libertad- Trujillo.

2000 «Los ceremoniales en Huaca de la Luna: un análisis de los espacios arquitectónicos». En: S. Uceda, E. Mujica y R. Morales (eds.) Investigacionesen la Huaca de la Luna 1997, pp. 205-215. Facultad de Ciencias Sociales. Universidad Nacional de Trujillo.

2004 «Paradigmas de la Arqueología Moche». En: S. Uceda, E. Mujica y R. Morales (eds.) Investigaciones en la Huaca de la Luna 2003, pp. 229-235. Trujillo: Facultad de Ciencias Sociales de la Universidad Nacional de Trujillo.

2008 «En busca de los palacios de los reyes Moche». En: K. Makowski (comp.) Señores de los reinos de la luna, vol.1: 111-127. Lima: BCP.

2010 «Los contextos urbanos de producción artesanal en el complejo arqueológico de las Huacas del Sol y de la Luna». En: Bulletin de I' InstitutFrancais D’ ÉtudesAndines. Tome $39 \mathrm{~N}^{\circ} 2$. Columbie Equateur Pérou Bolivie.

UCEDA, Santiago; Moisés TUFINIO y Elías MUJICA

2011 «El Templo Nuevo de Huaca de la Luna». Arkinka, Revista de Arquitectura, Diseño y Construcción, pp. 86-99. Lima, Arkinka S. A.

VARELA, Gonzalo

1992 Niklas Luhmann en México. Universidad Autónoma Metropolitana Xochimilco, Departamento de Política y Cultura, Mexico, D.F.

VAUGHN, Kevin J.

2004 «Households, Crafts and Feasting in the Ancient Andes: The Village Context of early Nasca Craft Consumption». Latin American Antiquity 15(1): 61-68. Societyfor American Archaeology.

WESTER, Carlos

2010 Chotuna-Chornancap. Templos, Rituales y Ancestros Lambayeque. Agosto 2010

ZAVALETA, Enrique; Alexis REATEGUI y Silvana BARBOZA

2012 «Excavaciones en el sector noroeste del Núcleo Urbano». En: S. Uceda y R. Morales (eds.) Informe Técnico 2011, Proyecto Arqueológico Huaca de la Luna, pp. 479- 529. Trujillo: Facultad de Ciencias Sociales de la Universidad Nacional de Trujillo. 